Sun, Y., Bak, B., Schoenmakers, N., van Trotsenburg, A.S.P., Oostdijk, W., Voshol, P., Cambridge, E., White, J.K., le Tissier, P., Gharavy, S.N.M., Martinez-Barbera, J.P.,

Stokvis-Brantsma, W.H., Vulsma, T., Kempers, M.J., Persani, L., Campi, I., Bonomi, M., Beck-Peccoz, P., Zhu, H., Davis, T.M., Hokken-Koelega, A.C.S., Del Blanco, D.G., Rangasami, J., Ruivenkamp, C.A.L., Laros, J.F.J., Kriek, M., Kant, S.G., Bosch, C.A.J., Biermasz, N.R., Appelman-Dijkstra, N.M., Corssmit, E.P., Hovens, G.C.J., Pereira, A.M., den Dunnen, J.T., Wade, M.G., Breuning, M.H., Hennekam, R.C., Chatterjee, K., Dattani, M.T., Wit, M.J . \& Bernard, D.J . (2012). Loss-of-funcation mutations in IGSFI cause an Xlinked syndrome of central hypothyroidism and testicular englargement. NATURE GENETICS, 44(12), 1375-1383.

(C) 2012 Nature Publishing Group, a division of Macmillan Publishers Limited. All Rights Reserved.

This is pre-copy-editing, author-produced version of an article accepted for publication in Nature Genetics following peer review. The definitive published version (see citation above) is located on the article abstract page of the publisher, Nature Publishing Group.

This version was made available in the UWA Research Repository on $5^{\text {th }}$ December 2013, in compliance with the publisher's policies on archiving in institutional repositories.

Use of the article is subject to copyright law. 


\section{Loss-of-function mutations in IGSF1 cause an X-linked syndrome of central hypothyroidism and testicular enlargement}

Yu Sun ${ }^{1,21}$, Beata Bak ${ }^{2,21}$, Nadia Schoenmakers ${ }^{3,21}$, A.S. Paul van Trotsenburg ${ }^{4,21}$, Wilma Oostdijk ${ }^{5}$, Peter Voshol ${ }^{3}$, Emma Cambridge ${ }^{6}$, Jacqueline K. White ${ }^{6}$, Paul le Tissier ${ }^{7,8}$, S. Neda Mousavy Gharavy ${ }^{9}$, Juan P. Martinez-Barbera ${ }^{9}$, Wilhelmina H. Stokvis-Brantsma ${ }^{5}$, Thomas Vulsma ${ }^{4}$, Marlies J.

Kempers ${ }^{4,10}$, Luca Persani ${ }^{11,12}$, Irene Campi ${ }^{11,13}$, Marco Bonomi ${ }^{11,12}$, Paolo Beck-Peccoz ${ }^{11,13}$, Hongdong Zhu $^{14}$, Timothy M.E. Davis ${ }^{14}$, Anita C.S. Hokken-Koelega ${ }^{15}$, Daria Gorbenko Del Blanco ${ }^{15}$, Jayanti J. Rangasami $^{16}$, Claudia A.L. Ruivenkamp ${ }^{1}$, Jeroen F.J. Laros ${ }^{1}$, Marjolein Kriek ${ }^{1}$, Sarina G. Kant ${ }^{1}$, Cathy A.J. Bosch ${ }^{1}$,Nienke R. Biermasz ${ }^{17}$, Natasha M. Appelman-Dijkstra ${ }^{17}$, Eleonora P. Corssmit ${ }^{17}$, Guido C.J.Hovens ${ }^{17}$, Alberto M. Pereira ${ }^{17}$, Johan T. den Dunnen ${ }^{1,18}$, Michael G. Wade ${ }^{19}$, Martijn H. Breuning ${ }^{1}$, Raoul C. Hennekam ${ }^{4}$, Krishna Chatterjee ${ }^{3,22}$, Mehul T. Dattani ${ }^{20,22}$, Jan M. Wit ${ }^{5,22}$, Daniel J. Bernard ${ }^{2,22}$ ${ }^{1}$ Center for Human and Clinical Genetics, Leiden University Medical Center, Leiden, The Netherlands ${ }^{2}$ Department of Pharmacology and Therapeutics, McGill University, 3655 Promenade Sir William Osler, suite 1315, Montréal, Québec (Canada), H3G 1 Y6

${ }^{3}$ Institute of Metabolic Science, Metabolic Research Laboratories, Addenbrooke's Hospital, University of Cambridge, Cambridge, CB2 0QQ, United Kingdom

${ }^{4}$ Department of Pediatric Endocrinology, Emma Children's Hospital, Academic Medical Center, Amsterdam, The Netherlands

${ }^{5}$ Department of Pediatrics, Leiden University Medical Center, Leiden, The Netherlands

${ }^{6}$ The Sanger Institute Mouse Genetics Project, Wellcome Trust Sanger Institute, Wellcome Trust Genome Campus, Hinxton, CB10 1SA, United Kingdom

${ }^{7}$ Neural Development Unit, UCL Institute of Child Health London; United Kingdom

${ }^{8}$ Division of Molecular Neuroendocrinology, National Institute for Medical Research, Mill Hill, London, United Kingdom

${ }^{9}$ Neural Development Unit, UCL Institute of Child Health, 30 Guilford Street, WC1N 1EH London, United Kingdom

${ }^{10}$ Department of Human Genetics, Radboud University Nijmegen Medical Center, Nijmegen, The Netherlands

${ }^{11}$ Department of Clinical Sciences \& Community Health, Università degli Studi di Milano, Italy

${ }^{12}$ Division of Endocrine and Metabolic Disorders, IRCCS Istituto Auxologico Italiano, Milan, Italy

${ }^{13}$ Endocrine Unit, Fondazione IRCCS Ca'Granda, Milan, Italy

${ }^{14}$ School of Medicine and Pharmacology, Fremantle Hospital Unit, The University of Western Australia, Australia 
${ }^{15}$ Department of Pediatrics, subdivision of Endocrinology, Erasmus MC-Sophia Children's Hospital, Rotterdam, The Netherlands

${ }^{16}$ Department of Paediatrics, West Middlesex University Hospital, Isleworth, Middlesex, United Kingdom

${ }^{17}$ Department of Endocrinology and Metabolic Disorders, Leiden University Medical Center, Leiden, The Netherlands

${ }^{18}$ Leiden Genome Technology Center, Leiden University Medical Center, Leiden, The Netherlands

${ }^{19}$ Hazard Identification Division, Environmental Health Science and Research Bureau, Health Canada, Ottawa, Ontario, Canada

${ }^{20}$ Developmental Endocrinology Research Group, Clinical and Molecular Genetics Unit, UCL Institute of Child Health, London, United Kingdom

${ }^{21}$ These authors contributed equally to this work

${ }^{22}$ These authors jointly directed this work

Correspondence to: Jan M Wit (¡.m.wit@lumc.nl), Daniel J Bernard (daniel.bernard@mcgill.ca), Krishna Chatterjee (kkc1@medschl.cam.ac.uk) and Mehul Dattani (m.dattani@ucl.ac.uk).

Prof. J. M. Wit, Department of Pediatrics, J6S, Leiden University Medical Center, P.O.Box 9600, 2300RC, Leiden, The Netherlands, Telephone: +31 71 5262824, Fax: +31 715248198

Dr. D. J. Bernard, Department of Pharmacology and Therapeutics, McGill University, 3655 Promenade Sir William Osler, suite 1315, Montréal, Québec, Canada, H3G 1Y6, Telephone: +11 15143982525 , Fax: +11-1-514-398-6705

Prof. K.Chatterjee, Institute of Metabolic Science, Metabolic Research Laboratories, Addenbrooke's Hospital, University of Cambridge, Cambridge, CB2 0QQ, United Kingdom, Telephone: +44 1223 336842, Fax: +44 1223330598

Prof.M.T.Dattani, Developmental Endocrinology Research Group, Clinical and Molecular Genetics Unit, UCL Institute of Child Health, London, United Kingdom, Telephone: +44 207 9052657, Fax: +44 2074046191 
Congenital central hypothyroidism occurs either in isolation or in conjunction with other pituitary hormone deficits. Using exome and candidate gene sequencing, we identified eight distinct mutations and two deletions in IGSF1 in males from eleven unrelated families with central hypothyroidism, testicular enlargement, and variably low prolactin concentrations. IGSF1 is a membrane glycoprotein highly expressed in the anterior pituitary gland and the identified mutations impair its trafficking to the cell surface in heterologous cells. Igsf1-deficient male mice show diminished pituitary and serum thyroid-stimulating hormone (TSH) concentrations, reduced pituitary thyrotropin-releasing hormone (TRH) receptor expression, decreased triiodothyronine concentrations, and increased body mass. Collectively, our observations delineate a novel X-linked disorder in which loss-of-function mutations in IGSF1 cause central hypothyroidism, likely secondary to an associated impairment in pituitary TRH signaling.

The index case in family A (A-III.11; Fig. 1a) was diagnosed with central hypothyroidism by neonatal screening for congenital hypothyroidism. His cousin (A-III.7), when referred for growth failure at 7.3 years, had central hypothyroidism, partial growth hormone (GH) deficiency and low prolactin (Table 1). In early adolescence, testicular growth advanced normally in both boys, but testes continued to grow beyond the reference range (Table 1 ). In contrast, serum testosterone (T) remained inappropriately low for testicular size until 15.2 and 14.2 years, respectively, leading to a late growth spurt and delayed pubic hair development. Subsequent testing of the maternal grandfather (A-I.4) showed central hypothyroidism (Table 1 ). $X$ chromosome exome sequencing in the two cousins (Supplementary Table 1) uncovered a 27nt deletion, c.2137_2163del (p.Ala713_Lys721del) in Xq25linked IGSF1. The same deletion was present in the grandfather (A-I.4) and another male relative (AII.4) with the same phenotype (Table 1; Fig. 1a). Independent whole exome sequencing of two brothers (B-III.7 and B-III.8) with central hypothyroidism in family B (Table 1; Fig. 1b; Supplementary Table 1) revealed a nonsense mutation, c.2931G>A (p.Trp977X), also in IGSF1 (Fig. 1c). B-III.7 and BIII.8 presented in infancy with prolonged neonatal jaundice, but two affected relatives harboring the same mutation were only diagnosed with central hypothyroidism following genetic screening at 65.5 (B-I.4) and 43.3 (B-II.11) years (Fig. 1b).

We found further IGSF1 variants in seven Dutch (C-I) and two Italian ( $\mathrm{J}$ and $\mathrm{K}$ ) families characterized by male-specific central hypothyroidism (Fig. 1c; Table 1; Supplementary Fig. 1). Most Dutch and Italian (family J) cases were detected through neonatal screening for congenital hypothyroidism (T4 and TSH). Thyroid function tests at diagnosis are shown in Supplementary Table 2. Mean (SD) serum FT4 level was 79 (13) \% of the lower limit of the reference range for age and assays. Except for two infants with lower values, all ranged between $67-94 \%$. Serum TSH was within the reference range in all cases (range 0.8-6.0 mU/L, mean $2.6 \mathrm{mU} / \mathrm{L}$ ). The FT4/TSH ratio was therefore lower than in controls (3.94 vs. 5.73, Mann-Whitney test, $p=0.002$ ). Mean (SD) serum T3 in nine 1-3 week old IGSF1-deficient infants was 98 (12) \% of the lower limit of the age reference (range $83-121 \%)^{1}$. In seven older cases, T3 was in the lower half of the reference range. Within families, we observed considerable differences in the extent of hypothyroidism.

In eight infants (2.5-5 weeks) and eight older patients (0.4-65.5 years), standard TRH tests were conducted (Supplementary Table 2). In the infants, the TSH peak was 4.5-16.0 mU/L. A similar range was observed in previous reports on congenital central hypothyroidism ${ }^{2,3}$, and is lower than observed in age-matched controls (14-37 mU/L) $)^{3}$. At later ages (7.3-63 years), TSH peaks were between 4.3-8.5 $\mathrm{mU} / \mathrm{L}$, which is in the lower half of the reported reference ranges for males $\left(3.7-12.5 \mathrm{mU} / \mathrm{L}^{4}\right.$ or 4.1 $13.9 \mathrm{mU} / \mathrm{L}^{5}$ ). In eight patients, the increment of serum FT4 [mean (SD) 14.2 (7.9)\%] was lower than that reported for controls [mean (SEM) 23.9 (2.7)\%], but the FT3 response to TRH was normal (36.3\% vs. $41.8 \%$ in controls ${ }^{6,7}$ (Supplementary Table 3 ). We could demonstrate central hypothyroidism in five of twenty female heterozygous carriers (data not shown). 
Serum prolactin concentrations were decreased in 18/26 patients (Table 1). Cases A-III.7, H-III.3, IIII.2 and K-II.3 showed growth retardation in childhood, associated with biochemical GH insufficiency, and were treated with biosynthetic $\mathrm{GH}$. In young adulthood, $\mathrm{GH}$ stimulation tests were normal in the three patients who had discontinued treatment. Details are presented in the Supplementary Note. In three patients, magnetic resonance imaging (MRI), performed because of macrocephaly (A-III.11), central hypothyroidism (C-III.1), and GH deficiency (K-II.3), was abnormal, showing a fronto-parietal hygroma, hypoplasia of the corpus callosum and small stalk lesion, respectively. In eight other cases, the MRI was normal.

Testicular development showed a characteristic pattern of a normal testicular volume in childhood, an increase of testicular volume from approximately 11 years onward while serum testosterone was still low, relatively large testes for serum testosterone ( $>2$ years advance) in adolescence, and adult macroorchidism ( $>30 \mathrm{ml}$ by Prader orchidometer, $>18.3 \mathrm{ml}$ by ultrasound) ${ }^{8}$ (Table 1). No abnormalities were observed in testis morphology by ultrasound. In 10 out of 11 evaluable cases testosterone production was delayed, defined as a late rise of serum testosterone $(<0.8 \mathrm{nmol} / \mathrm{L}=<23$ $\mathrm{ng} / \mathrm{dL}$ at 13.0 years $^{9}$ ) and/or a pubertal growth spurt $>2$ years delayed (compared with Dutch reference data ${ }^{10}$ ).

Table 2 shows the most recent data on height, body mass index (BMI), and pituitary-gonadal hormones. Mean height was close to the average of population references, but BMI was higher than 25 in 11 out of 13 adults and higher than +2 SDS in 5 out of 13 children. Plasma testosterone was normal in most cases. A-I.4, who underwent surgery for testicular torsion and in whom the remaining testis was atrophic, had low testosterone and elevated gonadotropins before the start of testosterone substitution, and currently his inhibin B and anti-Müllerian hormone (AMH) concentrations are very low. The two subjects (D-I.3 and F-II.8) with severe obesity had low plasma testosterone, but because of their low plasma SHBG, the free androgen index was normal. Plasma $\mathrm{LH}, \mathrm{FSH}$, inhibin $\mathrm{B}$ and anti-Müllerian hormone $(\mathrm{AMH})$ were within reference ranges in the majority of cases, but plasma FSH was always higher than $\mathrm{LH}$, and above the reference range in six cases. The response to $\mathrm{GnRH}(100 \mu \mathrm{g}$ i.v.) was higher for $\mathrm{LH}$ than for FSH in all except two subjects. Inhibin B tended to be high (elevated in 4 subjects) and $\mathrm{AMH}$ was relatively low (decreased in 5 subjects). Serum HDL and LDL cholesterol, triglycerides, glucose, insulin and C-peptide did not indicate metabolic syndrome (not shown).

Figure 1c summarizes the identified IGSF1 mutations. Families $C$ and D harboured the same single nucleotide deletion [c.2248del (p.Glu750LysfsX28)]. In families E and F, we observed submicroscopic gene deletions of different sizes that included IGSF1 and no other annotated genes. Affected members of families $\mathrm{G}, \mathrm{H}, \mathrm{I}$ and $\mathrm{K}$ bear missense or nonsense mutations and family $\mathrm{J}$ a single nucleotide insertion [c.3596_3597insT (p.Glu1200fsX3)]. All variants were confirmed by Sanger sequencing (Supplementary Table 4), map to conserved regions of the gene, are not present in available databases (dbSNP, 1000 Genomes Project, LOVD, HGMD, GoNL), and were not previously reported.

IGSF1 encodes a plasma membrane immunoglobulin superfamily glycoprotein ${ }^{11,12}$. The canonical IGSF1 protein possesses 12 C2-type Ig loops, a transmembrane domain, and a short intracellular Ctail (Fig. 1c). A hydrophobic linker separating Ig loops 5 and 6 targets the protein for obligate cotranslational proteolysis such that only the C-terminal domain (CTD) traffics to the plasma membrane ${ }^{13}$. IGSF1/Igsf1 mRNA is abundantly expressed in Rathke's pouch (the developing pituitary primordium; Fig. 2a) and in adult pituitary gland and testis ${ }^{13-17}$ (Supplementary Fig. 2). IGSF1 protein is detected in murine thyrotropes, somatotropes, and lactotropes, but not in gonadotropes (Fig. $\mathbf{2 b}$ ) or in testis (not shown). 
The phenotypes of patients with intragenic mutations are highly similar to those of individuals with complete IGSF1 deletions (families E and F) (Table 1), suggesting loss of IGSF1 function in all cases. The identified mutations in families A-D and G-K map to the IGSF1-CTD coding region (Fig. 1c). We therefore examined expression and post-translational regulation of IGSF1 mutants in heterologous HEK293 cells. Wild-type (WT) IGSF1 migrated as a 140-150 kDa doublet in western blot analysis (Fig. 3a, lane 2), reflecting the mature $\mathrm{N}$-glycosylated or immature endoplasmic reticulum (ER) resident

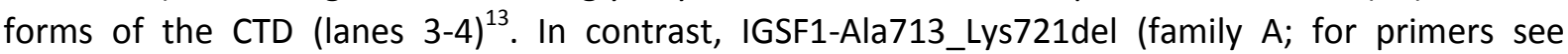
Supplementary Table 5) migrated predominantly as an immature form (Fig. 3a, lanes 5-7). Similar migratory patterns were observed for IGSF1-Ser863Phe (Fig. 3a; family G; lanes 8-10) and the other two missense mutants (Supplementary Fig. 3a; Family H, Cys947Arg; Family K, Ser770Asn; lanes 611). The nonsense mutants in families B/I (Trp977X, Fig. 3a, lanes 11-13; and Trp1173X, Supplementary Fig. 3a, lanes 17-19) and frame-shift mutants in families C/D (Glu750LysfsX28) and J (Glu1200ArgfsX3) (Supplementary Fig. 3a, lanes 3-5, 12-14) possessed immature sugars and were truncated relative to wild-type IGSF1. Based on their patterns of glycosylation, the identified IGSF1 mutants appeared to be retained in the ER.

To assess plasma membrane trafficking, we transfected HEK293 cells with WT and mutant IGSF1 constructs and detected the expressed proteins by immunofluorescence with an antibody directed against the N-terminus of IGSF1-CTD. Membrane staining was observed in non-permeabilized cells transfected with IGSF1-WT (Fig. 3b). A similar pattern was observed with IGSF1-Ala713_Lys721del and the three missense mutants (Fig. 3b, Supplementary Fig. 3b); however, cell surface biotinylation demonstrated that mutant proteins reached the plasma membrane with poor efficiency and with distinct glycosylation patterns compared to WT (Fig. 3c). Membrane signals were never detected in non-permeabilized cells transfected with IGSF1-Trp977X (Fig. 3b) or the other truncated forms of the protein (Supplementary Fig. 3b). We did not detect secreted proteins in the culture medium (not shown). In contrast, we observed a strong intracellular staining pattern in permeabilized cells with all constructs (Fig. 3b, Supplementary Fig. 3b), confirming expression of the mutant proteins. Thus, the identified mutations block or significantly impair IGSF1-CTD plasma membrane trafficking.

To establish a causal link between loss of IGSF1 function and central hypothyroidism, we examined pituitary and thyroid function in lgsf1-deficient mice ${ }^{17}$ (Supplementary Fig. 4). Messenger RNA expression for various pituitary hormone-encoding genes, including Tshb, did not differ between control and Igsf1-deficient mice (Fig. 4a, Supplementary Fig. 5a). In contrast, both pituitary and serum TSH were significantly reduced in adult Igsf1-deficient males (Fig. 4b,c). Pituitary prolactin content was unaffected (Supplementary Fig. 5b). Whereas circulating T3 concentrations were decreased in Igsf1-deficient males (Fig. 4d), T4/FT4 concentrations were similar to controls in the majority of cases and thyroid histology appeared normal (Supplementary Fig. $\mathbf{5 c}$,d and not shown). Reduced TSH synthesis and secretion (Fig. $\mathbf{4 b}, \mathbf{c}$ ) in the face of normal Tshb mRNA expression (Fig. 4a) in Igsf1-deficient mouse pituitaries suggested impaired TRH signaling. Consistent with this idea, pituitary Trhr mRNA was reduced and hypothalamic Trh mRNA increased in Igsf1-deficient mice relative to controls (Fig. 4e,f). Pituitary Gnrhr mRNA expression was unaltered (not shown). Finally, Igsf1-deficient males were heavier than their control littermates $(29.9 \pm 0.4$ vs. $28.2 \pm 0.3 \mathrm{~g}$ at 12 weeks, $\mathrm{p}=0.004)$. Thus, adult male Igsf1-deficient mice display several characteristics of central hypothyroidism.

IGSF1 was initially hypothesized to function as a pituitary inhibin co-receptor ${ }^{15,18,19}$, raising the possibility that macroorchidism in our patients might be linked to loss of inhibin action and therefore enhanced FSH secretion. However, IGSF1's putative role as an inhibin co-receptor has been challenged by more recent binding and in vivo data ${ }^{17,19}$. In our patients, serum FSH was higher than LH but exceeded the reference range in only six cases (Table 2). Moreover, male Igsf1-deficient mice 
are fertile and have normal testicular size and FSH ( ${ }^{17}$ and Supplementary Figs. 5a,e). Therefore, at present, the mechanisms of testicular enlargement in our patients are unresolved.

In summary, our data delineate a novel X-linked disorder in which loss-of-function mutations in IGSF1 cause central hypothyroidism, testis enlargement, and variable prolactin and GH deficiency. The identified human IGSF1 defects impair either expression or membrane trafficking of the IGSF1 Cterminal domain, consistent with a loss of protein function. Igsf1 deletion decreases pituitary and circulating TSH in mice, perhaps secondary to impaired TRH receptor signaling. Loss of IGSF1 function was associated with profound hypothyroxinemia in some patients, with the attendant risk of neurodevelopmental delay, if untreated. In other patients, hypothyroxinemia was less severe, but untreated subclinical hypothyroidism is associated with adverse cardiometabolic risk, which can be reversed by thyroxine treatment ${ }^{20-22}$. Thus, following genetic ascertainment of future cases, biochemical screening and thyroxine treatment of affected family members will be of significant clinical benefit. Collectively, our observations uncover a completely unexpected and clinically relevant role for IGSF1 in pituitary and testicular function.

\section{URLS}

RefSeq, http://www.ncbi.nlm.nih.gov/RefSeq/; dbSNP, http://www.ncbi.nlm.nih.gov/projects/SNP/; 1000 Genomes Project, http://www.1000genomes.org/; Hapmap Project, http://hapmap.ncbi.nlm.nih.gov/; Uniprot, http://www.uniprot.org; Human Splicing Finder, http://www.umd.be/HSF/; $\quad$ BWA, $\quad$ http://bio-bwa.sourceforge.net/; $\quad$ Samtools, http://samtools.sourceforge.net/; GMAP, http://research-pub.gene.com/gmap/; Seattleseq Annotation, http://snp.gs.washington.edu/SeattleSeqAnnotation131/; Sift, http://sift.jcvi.org/; polyphen-2, http://genetics.bwh.harvard.edu/pph2/; LOVD IGSF1 database, www.lovd.nl/igsf1; Xchromosome exome sequencing, http://databases.lovd.nl/shared/individuals/00000209 and http://databases.lovd.nl/shared/individuals/00000208.

\section{Methods}

Methods and associated references are available in the online version of the paper at http://www.nature.com/naturegenetics/.

\section{Accession number}

The IGSF1 reference sequence is deposited in the NCBI RefSeq database under the accession code NM_001170961.1.

\section{Acknowledgments}

We thank the subjects and their families for participating. Our work was supported in part by a grant from the China Scholarship Council (to Y.S.); an NSERC Doctoral Research Award (to B.B.), an NSERC Discovery Grant 341801-07 and an FRSQ Chercheur boursier senior award (to D.J.B.); grants from the Wellcome Trust (095564 to N.S and K.C.; WT077157/Z/05/Z, to E.C. and J.K.W.; 084361, 078432, and 086545 to J.P.M-B.), the National Institutes of Health Research Cambridge Biomedical Research Centre (to N.S and K.C.), the UK MRC (U117570590 to P.L.T.); a National Health and Medical 
Research Council of Australia Practitioner Fellowship (to T.M.E.D.); the Dutch Growth Research Foundation (D.G.D.B.); the Young Investigator grant of the Italian Ministry of Health and Instituto Auxologico Italiano IRCCS (GR-2008-1137632 to M.B.); and the Great Ormond Street Children's Hospital Charity (to M.T.D.). The authors thank Xiao-Hui Liao from Dr. Samuel Refetoff's laboratory (Departments of Medicine, Pediatrics and Genetics, The University of Chicago, supported by NIH grant DK15700) for measuring T4, T3, FT4I and TSH in mice, and Dr. Peter Scheiffele for the IGSF1CTD antibody, Drs. Sarah Kimmins and Peter Bisschop for human testis and pituitary RNA, respectively. We also thank Dr. H. Bikker (DNA Laboratory AMC, Amsterdam), Dr. J.C.Moreno and Dr. A.Escudero (Thyroid Molecular Laboratory, Institute for Medical and Molecular Genetics, La Paz University Hospital, Madrid, Spain), Dr. E. Aten (Center for Human and Clinical Genetics, LUMC and Leiden Genome Technology Center), Dr. M. Losekoot (Laboratory for Diagnostic Genome Analysis, LUMC), Dr. E. Endert (Endocrine Laboratory AMC, Amsterdam), Dr. Y. de Rijke and Prof. F.J. de Jong (Endocrine Laboratory ErasmusMC, Rotterdam), Prof. J.W.A. Smit (LUMC), Dr. R.van Rijn (Department of Radiology, AMC, Amsterdam) and Dr. E.L. van Persijn-van Meerten (Department of Radiology, LUMC) for technical support and advice. We thank Stella Tran and Xiang Zhou (McGill University) for assistance with collection of mouse serum samples. We acknowledge the help of Dr. N. Zwaveling, Dr. J. Gosen, Dr. E.J. Schroor, Dr. L.C.G. de Graaff and G. Radetti for providing clinical data. We acknowledge The Eastern Region Sequencing and Informatics Hub (EASIH, www.easih.ac.uk), who undertook sequencing and preliminary bioinformatic analyses of data from the UK families.

\section{Author contributions}

Y.S., J.T.d.D., M.K., N.S. and K.C. developed the exome sequencing protocol. A.S.P.v.T., W.O., S.G.K., N.B., N.A-D., A.M.P., M.H.B., R.C.H., M.D., N.S., L.P., I.C., M.B., P. B-P., H.D., T.D., K.C., A.C.S.H-K, D.G.D.B. and J.M.W. designed the clinical research studies. Y.S., J.F.J.L. and N.S. performed bioinformatics analyses, mutational analysis and genotyping. B.B. generated the mutant IGSF1 expression vectors and performed all associated biochemical analyses; maintained the mouse colony, collected all mouse tissues and plasma, and analyzed pituitary gene expression; and prepared figures. D.J.B. generated the mouse model; supervised all in vitro and mouse work; participated in data collection and construction of the figures. P.V. and M.G.W. contributed to murine phenotyping. E.C, J.K.W., and M.G.W. performed murine T4 measurements. P.L.T. performed measurements of pituitary TSH and PRL content. S.N.M.G. and J.P.M-B. carried out the IGSF1 expression studies in mouse and human embryos. C.A.L.R. and C.A.J.B. performed and analysed the microarray and hybridization experiments. A.S.P.v.T, W.O., W.H.S-B., T.V., M.K., L.P., I.C., M.B., P.B.-P, H.Z., T.M.E.D., A.C.S.H-K., D.G., J.J.R., S.G.K., N.B., N.A-D., A.M.P., G.C.J.H, E.P.C, M.H.B., R.C.H., A.C.S.H-K. and M.D. contributed to clinical evaluations and the delineation of the subject phenotypes. Y.S., B.B., N.S., A.S.P.v.T., K.C., M.T.D., R.C.H., D.J.B. and J.M.W. prepared the manuscript. D.J.B., J.M.W., K.C., and M.T.D. conceived and supervised the study.

\section{Competing financial interests}

The authors declare no competing financial interests. 


\section{Figure legends:}

Figure 1: IGSF1 mutations identified in patients with central hypothyroidism. (a) Pedigree of family A. Small horizontal lines signify that the mutation was confirmed. (b) Pedigree of family B. (c) Schematic representation of IGSF1 protein domain structure and relative positions of identified mutations.

Figure 2: IGSF1 is expressed in anterior pituitary gland. (a) Expression of IGSF1/Igsf1 mRNA in murine embryonic day 12.5 and human embryo Carnegie stage 18 Rathke's pouch progenitors as detected by in situ hybridization. Scale bars, $10 \mu \mathrm{m}$. (b) Immunofluorescence using IGSF1-CTD antibody and antibodies against the indicated anterior pituitary hormones (TSH: thyrotropes; GH: somatotropes; prolactin: lactotropes; LH: gonadotropes) was performed in WT E18.5 mouse pituitary. Scale bars, 10 $\mu \mathrm{m}$.

Figure 3: Mutations in IGSF1 impair its plasma membrane trafficking. (a) HEK293 cells were transfected with pcDNA3 (empty vector) or the indicated wild-type or mutant IGSF1 expression vectors. Protein lysates were deglycosylated with either PNGaseF (P) or EndoH (E), resolved by SDSPAGE, and immunoblotted using an IGSF1-CTD antibody. Non-specific bands are indicated by *. (b) HEK293 cells were transfected with the same constructs as in (a). Expression of IGSF1-CTD was analyzed by immunofluorescence using the IGSF1-CTD antibody under non-permeabilizing and permeabilizing conditions. Nuclei were stained with DAPI (blue). Scale bars, $10 \mu \mathrm{m}$. (c) HEK293 cells were transfected with pcDNA3 or the indicated wild-type or mutant IGSF1 expression vectors. Membrane expression of IGSF1-CTD was analyzed by cell-surface biotinylation.

Figure 4: Igsf $1^{\Delta e x 1}$ mice have several characteristics of central hypothyroidism. (a) Pituitary Tshb mRNA levels in 12-week old wild-type and Igsf $1^{\Delta e x 1}$ mice ( $\left.N=6 / g e n o t y p e\right)$. (b) Pituitary TSH content in male wild-type and $\operatorname{lgsf1} 1^{\mathrm{\Delta ex} 1}$ mice ( $\mathrm{N}=6 /$ genotype). (c) Serum TSH levels in adult wild-type and $\operatorname{lgs} f 1^{\mathrm{\Delta ex} 1}$ mice ( $\mathrm{N}=6 /$ genotype). (d) Serum total $\mathrm{T3}$ levels in adult wild-type and $\operatorname{lgs} f 1^{\mathrm{\Delta ex1}}$ mice $(\mathrm{N}=14-$ 16/genotype). (e) Trhr mRNA levels in 12-week old wild-type and $\operatorname{lgsf1} 1^{\Delta \operatorname{ex} 1}$ mice ( $\mathrm{N}=6 /$ genotype). (f) Trh mRNA levels in 12-week old wild-type and $\operatorname{lgs} f 1^{\Delta \operatorname{ex} 1}$ mice ( $\left.N=5 / g e n o t y p e\right)$. Statistical significance was determined by two-tailed Student's t-test in each panel. 
Table 1. Clinical features of cases with IGSF1 variants (all males)

\begin{tabular}{|c|c|c|c|c|c|c|c|c|}
\hline Cases & $\begin{array}{l}\text { Nucleotide } \\
\text { alteration }\end{array}$ & $\begin{array}{l}\text { Amino-acid } \\
\text { alteration }\end{array}$ & Origin & $\begin{array}{l}\text { Age at diagnosis } \\
\text { of central } \\
\text { hypothyroidism }\end{array}$ & $\begin{array}{c}\text { Central } \\
\text { hypothyroidism }^{1}\end{array}$ & $\begin{array}{c}\text { PRL } \\
\text { deficiency }^{2}\end{array}$ & Age $(y r s)^{3}$ & $\begin{array}{c}\mathrm{R} / \mathrm{L} \text { testicular vol. }(\mathrm{ml}) \\
\text { [reference] }^{4}\end{array}$ \\
\hline A-III.11 & \multirow[t]{4}{*}{ c.2137_2163del } & \multirow[t]{4}{*}{ p.Ala713_Lys721del } & NL & 3 wks & + & - & 17.64 & $21 / 20$ [7.3-16] \\
\hline$A-I I I .7$ & & & $\mathrm{NL}$ & $7.3 \mathrm{yrs}$ & + & + & 21.36 & $30 / 26$ [8.5-18.3] \\
\hline$A-I I .4$ & & & NL & 51.5 yrs & + & - & 52.41 & $32 / 29[8.5-18.3]$ \\
\hline$A-I .4$ & & & $\mathrm{NL}$ & 74.1 yrs & + & - & 67.70 & 4/large $[8.5-18.3]^{5}$ \\
\hline$B-1 I I .7$ & \multirow[t]{4}{*}{ c. $2931 \mathrm{G}>\mathrm{A}$} & \multirow[t]{4}{*}{ p.Trp977X } & UK & 4 wks & + & + & 10.52 & $1.1 / 1.0[0.55-1.87]$ \\
\hline$B-I I I .8$ & & & UK & 7 wks & ++ & - & 7.95 & $1.8 / 1.5[0.45-0.92]$ \\
\hline$B-I I .11$ & & & UK & 43.3 yrs & + & + & 43.30 & $68 / 37$ [8.5-18.3] \\
\hline$B-1.4$ & & & UK & 65.9 yrs & + & - & 66.37 & $19.6 / 21.6[8.5-18.3]$ \\
\hline C-III.1 & c.2248del & p.Glu750LysfsX28 & $\mathrm{NL}$ & $3 \mathrm{wks}$ & + & + & 16.60 & $18 / 18[7.8-16.2]^{6}$ \\
\hline$D-I I I .3$ & \multirow[t]{3}{*}{ c.2248del } & \multirow[t]{3}{*}{ p.Glu750LysfsX28 } & $\mathrm{NL}$ & 3 wks & ++ & + & 10.46 & $1 / 1[0.55-1.87]$ \\
\hline$D-I I I .4$ & & & $\mathrm{NL}$ & $1 \mathrm{wk}$ & + & + & 3.79 & $0.8 / 0.8[0.32-0.70]$ \\
\hline$D-1.3$ & & & NL & 61 yrs & + & - & 62.75 & 21/16 [8.5-18.3] \\
\hline E-IV.1 & \multirow[t]{2}{*}{$126 \mathrm{~kb}$ deletion ${ }^{7}$} & & $\mathrm{NL}$ & $2 \mathrm{wks}$ & + & + & 20.57 & $>18.3[8.5-18.3]^{6}$ \\
\hline$E-I V .3$ & & & NL & $2.5 \mathrm{wks}$ & + & - & 22.37 & $34 / 25.5[8.5-18.3]$ \\
\hline F-IV.1 & \multirow[t]{3}{*}{$328 \mathrm{~kb}$ deletion ${ }^{8}$} & & $\mathrm{NL}$ & 3 wks & + & - & 12.70 & $12.2 / 8.4[4-13]$ \\
\hline$F-I V .2$ & & & NL & 3 wks & + & + & 9.44 & $1 / 0.9[0.5-1.35]$ \\
\hline$F-I I .8$ & & & NL & 57.5 yrs & + & + & 58.24 & $44.6 / 48.2[8.5-18.3]$ \\
\hline G-III.1 & \multirow[t]{3}{*}{$\mathrm{c} .2588 \mathrm{C}>\mathrm{T}$} & \multirow[t]{3}{*}{ p.Ser863Phe } & NL & 5 wks & + & + & 27.52 & $11.8 / 38[8.5-18.3]$ \\
\hline G-III.3 & & & $\mathrm{NL}$ & $2.5 \mathrm{wks}$ & + & + & 23.08 & $25.5 / 25.4[8.5-18.3]$ \\
\hline G-I.1 & & & $\mathrm{NL}$ & 63 yrs & + & + & 87.49 & $>>18.3[8.5-18.3]^{6}$ \\
\hline $\mathrm{H}-\mathrm{III} .2$ & \multirow[t]{2}{*}{ c.2839T $>C$} & \multirow[t]{2}{*}{ p.Cys947Arg } & $\mathrm{NL}$ & $6.5 \mathrm{yrs}$ & + & + & 18.36 & $22.7 / 22.7[8.5-18.3]$ \\
\hline$H-I I I .3$ & & & NL & 3 wks & + & + & 15.93 & $21.7 / 21.7[6.7-15.3]$ \\
\hline$I-I I I .2$ & c. $3518 \mathrm{G}>\mathrm{A}$ & p.Trp1173X & $\mathrm{NL}$ & $14.1 \mathrm{yrs}$ & + & + & 16.69 & $19 / 17[8-16.5]$ \\
\hline$J-I I I .1$ & \multirow[t]{2}{*}{ c.3596-3597insT } & \multirow[t]{2}{*}{ p.Glu1200fsX3 } & IT & 3 wks & + & + & 3.26 & $0.75 / 0.80[0.32-0.70]$ \\
\hline$J-I I I .2$ & & & IT & 2 wks & + & + & 0.16 & $0.58 / 0.58[0.30-0.65]^{6}$ \\
\hline$K-I I .3$ & c. $2309 \mathrm{G}>\mathrm{A}$ & p.Ser770Asn & IT & 10.6 yrs & + & + & 26.54 & $21.5 / 21.4[8.5-18.3]$ \\
\hline
\end{tabular}

${ }^{1}+$ indicates serum FT4 $50-99 \%$ of the lower limit of normal; ++ indicates $<50 \%$ of lower limit of normal. In all cases serum TSH was normal. 
${ }^{2}+$ indicates serum prolactin $<$ lower limit of normal.

${ }^{3}$ Age at sonographic determination of testicular volume.

${ }^{4}$ Sonographic testicular volume right/left $(\mathrm{ml})$ in comparison to age references ${ }^{8}$

${ }^{5}$ Self-reported unilateral macroorchidism, until the enlarged testis was removed after testicular torsion leading to complete infarction at 74 years; the size of the infarcted testis was $343 \mathrm{ml}$. The remaining testis was small and soft, with deficient testosterone secretion. Testosterone treatment was started at 76 years.

${ }^{6}$ Estimated based on Prader orchidometer ( $30 \mathrm{ml}$ by Prader orchidometer $=18.3 \mathrm{ml}$ by ultrasound, $2 \mathrm{ml}$ by Prader orchidometer $=0.58 \mathrm{ml}$ by ultrasound ${ }^{8}$ ).

${ }^{7}$ Arr Xq26.1q26.2(130.386.267-130.512.002)x1 (hg19)

${ }^{8}$ Arr Xq26.1q26.2(130.310.905-130.639.353)x1 (hg19) 
Table 2. Clinical and laboratory data

\begin{tabular}{|c|c|c|c|c|c|c|c|c|c|c|c|}
\hline Case & $\begin{array}{l}\text { Age } \\
\text { (yrs) }\end{array}$ & $\begin{array}{l}\text { T4 } \\
\text { R/ }\end{array}$ & $\begin{array}{l}\text { Height } \\
\text { SDS }^{1}\end{array}$ & $\begin{array}{l}\text { BMI }^{2} \\
\text { SDS }^{2}\end{array}$ & $\begin{array}{l}\text { LH } \\
(\mathrm{IU} / \mathrm{L})^{3}\end{array}$ & $\begin{array}{l}\text { FSH } \\
(\mathrm{IU} / \mathrm{L})^{3}\end{array}$ & $\begin{array}{l}\text { LHmax } \\
\text { to GnRH }\end{array}$ & $\begin{array}{l}\text { FSHmax } \\
\text { to GnRH }\end{array}$ & $\begin{array}{c}\mathrm{T} \\
(\mathrm{nmol} / \mathrm{L})^{3}\end{array}$ & $\begin{array}{c}\text { Inhibin B } \\
(\mathrm{ng} / \mathrm{L})^{4}\end{array}$ & $\begin{array}{c}\text { AMH } \\
(\mu \mathrm{g} / \mathrm{L})^{4}\end{array}$ \\
\hline A-III.11 & 17.64 & + & -0.2 & 2.6 & $1.0^{5}$ & $3.8^{5}$ & $13.1^{5}$ & $8.3^{5}$ & $1.1[1.0-16.3]^{5}$ & $328[80-300]$ & $16.6[10-100]$ \\
\hline$A-I I I .7$ & 21.36 & + & 1.0 & 1.8 & 3.6 & 10.6 & 18.9 & 18.7 & 17.6 & 237 & 12.4 \\
\hline$A-11.4$ & 52.41 & - & 0.3 & 2.5 & 3 & 17.9 & - & - & 12.7 & 199 & 5.6 \\
\hline$A-I .4$ & 86.70 & + & 0.2 & 4.3 & $15^{6}$ & $54^{6}$ & - & - & $4.8^{6}$ & $<10$ & 0.24 \\
\hline$B-I I I .7$ & 10.52 & + & 1.4 & 1.9 & $<1$ & 1.2 & - & - & $<0.3[0.2-1.2]$ & $91[20-300]$ & 97 [30-200] \\
\hline$B-1 I I .8$ & 7.95 & + & 0.7 & 2.2 & $<1$ & 3.1 & - & - & $<0.3[0.07-0.31]$ & $111[20-120]$ & $97[100-400]$ \\
\hline$B-I I .11$ & 43.29 & + & -0.2 & 3.3 & 3.7 & 10.1 & 29.6 & 22.6 & 16.8 & 279 & 7.4 \\
\hline$B-1.4$ & 66.37 & - & $\begin{array}{l}-0.6 \\
\end{array}$ & 2.1 & 2.1 & 11.0 & 30.8 & 36.7 & 18.7 & 192 & 6.2 \\
\hline C-III.1 & 17.39 & + & 0.6 & 2.0 & 3.2 & 3.8 & - & - & 17.2 & $299[80-300]$ & $14.0[10-100]$ \\
\hline$D-I I I .3$ & 10.46 & + & -0.4 & 0.8 & $<1$ & 2.9 & 1.4 & 15.4 & $<0.3[0.2-1.2]$ & $97[20-300]$ & $35.4[30-200]$ \\
\hline$D-I I I .4$ & 3.79 & + & -0.6 & 1.1 & $<1$ & 1.1 & - & - & $<0.3[0.07-0.28]$ & $192[20-100]$ & 207 [100-1000] \\
\hline$D-1.3$ & 62.75 & - & -1.2 & 7.7 & 2.5 & 6.3 & 22.2 & 14.1 & $10.1^{7}$ & 152 & 1.4 \\
\hline$E-I V .1$ & 20.57 & + & -0.5 & 1.0 & 1.3 & 4.8 & - & - & 13.4 & 454 & - \\
\hline$E-I V .3$ & 22.37 & + & 1.0 & 2.8 & 4.4 & 6.0 & 38.7 & 13.1 & 19 & 317 & 26.9 \\
\hline F-IV.1 & 12.70 & + & 1.1 & 2.2 & $<1$ & 2.5 & 9.4 & 5.1 & $4.2[0.4-9.5]$ & $533[80-300]$ & $50.2[10-100]$ \\
\hline F-IV.2 & 9.44 & + & 1.3 & 2.9 & $<1$ & $<1$ & - & - & $1.7[0.14-0.66]$ & $92[20-120]$ & $134[100-400]$ \\
\hline$F-I I .8$ & 58.24 & - & 1.4 & 8.6 & 3.5 & 8.6 & 21 & 15.3 & $5.1^{7}$ & 141 & 5.2 \\
\hline G-III.1 & 27.52 & + & -0.5 & 3.5 & 3.8 & 3.9 & 25 & 7.8 & 24 & 249 & 4.5 \\
\hline G-III.3 & 23.08 & + & 0.6 & 1.5 & 3.2 & 6.9 & 31.8 & 17.2 & 24 & 249 & 5.9 \\
\hline$G-I .1$ & 87.49 & + & -1.9 & 2.5 & - & - & - & - & - & - & - \\
\hline $\mathrm{H}-\mathrm{III.2}$ & 20.52 & + & -2.5 & 2.6 & 2.7 & 4.6 & - & - & 11.8 & 338 & 7.2 \\
\hline$H-I I I .3$ & 18.09 & + & -0.7 & 1.7 & 6.5 & 10.7 & - & - & 16.9 & 265 & 6.4 \\
\hline $1-I I I .2$ & 16.69 & + & -0.6 & 2.0 & $<1$ & 3.9 & 14.3 & 9.8 & $9.5[1.7-27.8]$ & 257 [80-300] & $3.3[10-100]$ \\
\hline J-III.1 & 3.26 & + & 0.1 & 1.0 & - & - & - & - & - & - & - \\
\hline J-III.2 & 0.16 & + & 0.5 & 1.4 & - & - & - & - & - & - & - \\
\hline$K-I I .3$ & 26.54 & + & 0.1 & 1.1 & 1.6 & 3.4 & 36.5 & 10.7 & 11.5 & 284 & 10.8 \\
\hline
\end{tabular}

${ }^{1}$ Height is expressed as standard deviation score (SDS) for national reference data for the Netherlands ${ }^{23}$, United Kingdom ${ }^{24}$ and Italy ${ }^{25}$. Median height 0.1 SDS.

${ }^{2} \mathrm{BMI}$ is expressed as SDS for Dutch references obtained in $1980^{26}$. Median BMI 2.1 SDS.

${ }^{3}$ Reference ranges for males $>17$ years: testosterone $11-35 \mathrm{nmol} / \mathrm{L}, \mathrm{LH}<0.1-15 \mathrm{U} / \mathrm{L}, \mathrm{FSH}<0.1-10 \mathrm{U} / \mathrm{L}$. Reference ranges for testosterone in boys (P10-P90) according to Von Schnakerburg et al

${ }^{4}$ Reference range for males >18 years: inhibin-B 150-400 ng/L, AMH 5-30 $\mathrm{\mu g} / \mathrm{L}$. Reference ranges for younger age groups are indicated (Dr.Y.de Rijke and Prof.F.J.de Jong, ErasmusMC, Rotterdam Netherlands).

${ }^{5} \mathrm{GnRH}$ test and testosterone performed at 15.19 years, before start of testosterone substitution therapy. 
${ }^{6} \mathrm{LH}, \mathrm{FSH}$ and testosterone before the start of testosterone substitution therapy (at 76 years).

${ }^{7}$ Because of low plasma sex hormone binding globulin (SHBG), free androgen index [FAl, (100 x testosterone)/SHBG] was high in D-I.3 (67, age reference 18-54) and normal in F-II.8 (46, age reference 30-53).

Abbreviations: $\mathrm{T} 4 \mathrm{R} /=\mathrm{L}$-thyroxine treatment. $\mathrm{T}$ = testosterone. $\mathrm{AMH}=$ anti-Müllerian hormone. 


\section{Methods}

\section{DNA isolation}

DNA was isolated from human whole blood by salting out (Puregene, Qiagen) following manufacturer's instructions.

\section{Exome enrichment and next generation sequencing}

$\mathrm{X}$-exome enrichment was carried out using Agilent's SureSelect $\mathrm{X}$ chromosome oligo capture library following manufacturer's protocol except DNA was hybridized with half of the suggested probe. Illumina GAll generated 51 bp paired-end reads. Reads overview in Supplementary Table 1. Whole exome sequencing was undertaken using SureSelect Human All Exon 50Mb Kit (Agilent Technologies). Sequencing was performed with SOLiD ${ }^{\text {TM }} 4$ System (Applied Biosystems).

Read mapping, variant calling, and annotation

For the X-exome data, reads were aligned to reference genome hg19 by BWA-0.5.8 ${ }^{28}$. Bam file manipulation and variant (SNVs and indels) calling was done by samtools-0.1.929. Deletion in family $A$ was detected by GMAP v3. 2011-03-28(alignment) ${ }^{30}$ and samtools-0.1.9 (variant calling). SeattleSeq Annot.131 was applied to annotate all variants. Variants in dbSNP131 and 1000 Genomes Project were filtered out for mutation screening. Whole exome experiments, sequencing and preliminary analyses were undertaken at Eastern Region Sequencing and Informatics Hub, using Genome Analysis Toolkit ${ }^{31}$.

\section{Filtering strategy}

In family A, variants shared by both boys were classified based on their function; only exonic and splice site variants were taken. We then filtered out all the variants present in local in-house exome sequencing database, dbSNP, 1000 Genomes Project, Leiden Open Variance Database (LOVD), and Hapmap Project with an allele frequency $>1 \%$ in Caucasian population, which yielded no promising results. We therefore checked the variant list generated by GMAP and samtools, as GMAP allows gap alignment and enables identification of larger insertions and deletions. The same filtering procedure was applied on those variants. For family B, we compared variants from the two brothers; only shared exonic and splice site variants were taken into the filtering step. We filtered out all variants present in databases above and the UK 10K genomes project, and focused on novel, shared homozygous or X-linked hemizygous variants, using public databases to identify plausible candidates.

\section{Sanger sequence analysis}

PCR was performed using Phire Hot Start II DNA polymerase (Finnzyme) following manufacturer's protocol (primers in Supplementary Table 4). Products were purified with QIAquick PCR purification kit (Qiagen), then mixed with $10 \mathrm{pmol}$ of forward or reverse primers and sequenced by Applied Biosystems 96-capillary 3730XL system.

\section{Microarray}

We carried out a cytogenetic whole-genome 2.7M array (Affymetrix) following manufacturer's protocol. In families C/D, this revealed the same haploblock of $23 \mathrm{Mb}$ around the deletion (rs929590 to rs16979902), suggesting common ancestral origin. No familial relationship is known for at least four generations. 


\section{Constructs}

The IGSF1-CTD antibody epitope of human Myc-IGSF1-HA construct (from Dr. Peter Scheiffele) was modified (QuikChange, Stratagene) to match the murine protein to facilitate detection with IGSF1CTD polyclonal antibody (Dr. Scheiffele). Mutations were introduced into the construct using QuikChange or Phusion (Thermo) (p.Ala713_Lys721del) site-directed mutagenesis (primers in Supplementary Table 5). Constructs were verified by sequencing (McGill University and Genome Québec Innovation Centre).

\section{Cell culture}

For western blotting and cell surface biotinylation, HEK293 cells were plated in 6-well plates, and transfected with $200 \mathrm{ng}$ of expression vector using Lipofectamine 2000 (Invitrogen) following manufacturer's instructions. For immunofluorescence, HEK293 cells were plated in 24-well plates on glass coverslips at 50,000 cells/well and transfected with 100 ng vector.

\section{Western blotting}

Whole cell extracts were prepared from transfected cells $24 \mathrm{~h}$ post-transfection using RIPA buffer. Protein lysates were deglycosylated using PNGaseF and EndoH (New England Biolabs), using manufacturer's instructions. Western blots were performed as previously described ${ }^{32}$.

\section{Cell Immunofluorescence}

Non-permeabilizing: IGSF1-CTD antiserum (1:500 in serum-free DMEM) was applied to cells for $2 \mathrm{~h}$ at $37^{\circ} \mathrm{C} / 5 \% \mathrm{CO}_{2}$. Cells were transferred to room temperature, washed $3 \mathrm{x}$ with serum-free DMEM and fixed with 4\% paraformaldehyde. Cells were washed 3x with PBS, incubated in 5\% BSA in PBS for $1 \mathrm{~h}$, secondary antibody (1:600 in 5\% BSA in PBS) was applied to cells for $1 \mathrm{~h}$, cells were washed $3 \mathrm{x}$ with PBS and mounted using aqueous media with DAPI. Permeabilizing: cells were fixed using $4 \%$ paraformaldehyde, washed 3x in PBS, incubated in 0.3\% Triton X-100 in PBS (PBSX), incubated in 5\% BSA in PBSX for $1 \mathrm{~h}$. IGSF1-CTD antiserum (1:500 in 5\% BSA in PBSX) was applied to cells for $2 \mathrm{~h}$. Cells were washed $3 x$ with PBS, secondary antibody (1:600 in 5\% BSA in PBSX) was applied for $1 \mathrm{~h}$, cells were washed $3 x$ with PBS, and mounted as above.

\section{Pituitary immunofluorescence}

The morning when a vaginal plug was detected was considered embryonic day (E) 0.5. E18.5 pregnant mice were sacrificed, embryo heads fixed overnight in $4 \% \mathrm{PFA}$ at $4^{\circ} \mathrm{C}$, embedded in paraffin, and sliced at $5 \mu \mathrm{m}$. Sections were treated as described before ${ }^{33}$. Nonspecific binding was blocked using 5\% BSA in PBS with 0.2\% Tween-20 (PBST). Sections were incubated with primary antibodies (IGSF1-CTD 1:500, and from Santacruz: TSH/LH 1:400, GH/prolactin, 1:200 in blocking buffer) overnight at $4^{\circ} \mathrm{C}$. Sections were washed $3 x$ with PBST, incubated in horse-anti-goat biotin antibody (1:150 in blocking buffer) for $1 \mathrm{~h}$, washed $3 \mathrm{x}$ with PBST, incubated in Streptavidin-Texas Red (1:400 in blocking buffer) and goat anti rabbit Alexa 488 (1:600) for 1h, washed 3x with PBST, and mounted as above.

\section{Cell surface biotinylation}

Transfected cells were washed $3 x$ with PBS and incubated in $1 \mathrm{ml} 0.5 \mathrm{mg} / \mathrm{mL}$ EZ-link-sulfo-NHS-LCbiotin (Thermo) for $30 \mathrm{~min}$ at $4^{\circ} \mathrm{C}$, washed $3 \mathrm{x}$ with $100 \mathrm{mM}$ glycine in PBS, harvested in lysis buffer 
(50 mM Tris pH 7.5, $150 \mathrm{mM} \mathrm{NaCl}, 1 \mathrm{mM}$ EDTA, 1\% Triton X-100), and lysed by sonication (9W, 10 seconds). Lysates were centrifuged, supernatant collected, and immunoprecipitation was carried out using anti-HA affinity beads (Sigma) following manufacturer's instructions. Lysates were then processed for western blotting as above. After blocking, membrane was incubated in $2.5 \%$ milk in TBST with 2 drops each of $A$ and $B$ reagents from Vectastain kit (Vector) for $30 \mathrm{~min}, 3 \times 10$ min washes in TBST and signal visualized using Western Lightning Plus-ECL kit (Perkin-Elmer).

\section{Animals}

Igsf1-deficient mice were described previously ${ }^{17}$. Tissue and blood collection was performed in accordance with institutional (McGill University) and federal guidelines.

\section{In situ hybridization}

In situ hybridization was performed as previously described ${ }^{34}$ using riboprobes from human IGSF1 cDNA clone 30387876 (IMAGE). Human embryonic material was provided by Human Developmental Biology Resource, supported by Medical Research Council Grant G0700089 and Wellcome Trust Grant 082557.

\section{Northern blotting}

Human pituitary RNA was from Netherlands Brain Bank, NBB number 02-055, in accordance with formal permission for a brain autopsy and use of human brain material and clinical information for research purposes. Human testicular RNA was obtained from Dr. Sarah Kimmins. Thirteen $\mu \mathrm{g}$ of each RNA were blotted as previously described ${ }^{17}$, using a probe spanning exons $18-20$ of murine Igsf1.

\section{Hormone measurements}

At diagnosis, serum FT4, TSH, T3 and prolactin were determined in laboratories of participating departments. At follow up, samples were investigated in Endocrine Laboratory, ErasmusMC, Rotterdam (inhibin B and $\mathrm{AMH}$ ), and Laboratory of Endocrinology and Radiochemistry, Academic Medical Center, Amsterdam (other measurements). Plasma LH and FSH were analysed on a Roche E170; intra and interassay variations: $<5 \%$. Plasma T3 was measured by in-house RIA; intra/interassay variations: $6.3 \% / 7.8 \%$. FT4, FT3, TSH, prolactin and GH were analysed by fluoroimmunoassay using Delfia 1232 Fluorometer (Perkin Elmer); intra/interassay variations: FT4 5.1\%/6.8\%, FT3 7.7\%/11.3\%, TSH 4.2\%/5.7\%, prolactin 3.4\%/5.3\%, and GH 3.8\%/6.2\%. Plasma testosterone was analysed by inhouse RIA; intra/interassay variations: $9.2 \% / 10.8 \%$. Insulin was analysed by chemiluminescence using Immulite 2000 (Siemens); intra/interassay variations: 3.7\%/5.1\%. Serum inhibin B and AMH were estimated using enzyme-immunometric methods (Beckman Coulter); for AMH the Gen II assay was used; intra/interassay variation was published previously ${ }^{35,36}$.

Murine pituitary TSH and PRL content measurement was previously described ${ }^{37}$, using reagents supplied by Prof. A.L. Parlow (NHPP, Torrance, CA). In Chicago, serum total T4/T3 concentrations were measured by coated tube RIAs (Siemens Medical Solutions Diagnostics) adapted for mouse. TSH was measured as described before ${ }^{38}$. Free T4 levels were estimated from total T4 and resin T4 uptake ratio and expressed as free T4 index (FT4I) as in ${ }^{39}$.

Quantitative PCR 
Murine RNA was extracted from whole pituitaries and $3 \mathrm{~mm}$ hypothalamic blocks according to following coordinates ${ }^{40}$ : anteroposterior-interaural 3.94 to $0.94 \mathrm{~mm}$, dorsoventral-interaural $2.5 \mathrm{~mm}$ and below, and $1.44 \mathrm{~mm}$ lateral. RNAs were extracted and reverse-transcribed $(2 \mu \mathrm{g})$ as previously described $^{32}$. qPCR was performed using Platinum SYBR Green qPCR SuperMix UDG (Invitrogen) and 0.4 pmol of each primer (see Supplementary Table 6) on a Corbett Rotor-Gene 6200 HRM (Corbett Life Science), using manufacturer's protocol. Transcript levels were normalized relative to ribosomal protein L19 (Rp/19) and analyzed using $2^{-\Delta \Delta C t}$ method $^{41,42}$.

\section{Statistics}

In Figure 4 and all supplemental figures, statistical significance taken at $p<0.05$ was determined by two-tailed Student's t-test. 


\section{Reference list}

1. Elmlinger,M.W., Kuhnel,W., Lambrecht,H.G., \& Ranke,M.B. Reference intervals from birth to adulthood for serum thyroxine (T4), triiodothyronine (T3), free T3, free T4, thyroxine binding globulin (TBG) and thyrotropin (TSH). Clin Chem. Lab Med. 39, 973-979 (2001).

2. Mehta,A. et al. Is the thyrotropin-releasing hormone test necessary in the diagnosis of central hypothyroidism in children. J Clin Endocrinol Metab 88, 5696-5703 (2003).

3. van Tijn,D.A., de Vijlder,J.J., \& Vulsma,T. Role of the thyrotropin-releasing hormone stimulation test in diagnosis of congenital central hypothyroidism in infants. $J$ Clin Endocrinol Metab 93, 410-419 (2008).

4. Faglia,G. et al. Plasma thyrotropin response to thyrotropin-releasing hormone in patients with pituitary and hypothalamic disorders. J Clin Endocrinol Metab 37, 595-601 (1973).

5. $\quad$ Crofton,P.M., Tepper,L.A., \& Kelnar,C.J. An evaluation of the thyrotrophin-releasing hormone stimulation test in paediatric clinical practice. Horm Res 69, 53-59 (2008).

6. Persani,L. et al. Evidence for the secretion of thyrotropin with enhanced bioactivity in syndromes of thyroid hormone resistance. J Clin Endocrinol Metab 78, 1034-1039 (1994).

7. Persani,L., Ferretti,E., Borgato,S., Faglia,G., \& Beck-Peccoz,P. Circulating thyrotropin bioactivity in sporadic central hypothyroidism. J Clin Endocrinol Metab 85, 3631-3635 (2000).

8. Goede,J. et al. Normative values for testicular volume measured by ultrasonography in a normal population from infancy to adolescence. Horm Res Paediatr 76, 56-64 (2011).

9. Dattani,M.T., Tziaferi,V., \& Hindmarsh,P.C. Evaluation of Disordered Puberty in Brook's Clinical Pediatric Endocrinology (eds. Brook,C.G.D., Clayton,P.E. \& Brown,R.S.) 213238 (Wiley-Blackwell, Oxford, 2009).

10. Mul,D. et al. Pubertal development in The Netherlands 1965-1997. Pediatr. Res. 50, 479-486 (2001).

11. Mazzarella,R., Pengue,G., Jones,J., Jones,C., \& Schlessinger,D. Cloning and expression of an immunoglobulin superfamily gene (IGSF1) in Xq25. Genomics 48, 157-162 (1998).

12. Frattini,A., Faranda,S., Redolfi,E., Allavena,P., \& Vezzoni,P. Identification and genomic organization of a gene coding for a new member of the cell adhesion molecule family mapping to Xq25. Gene 214, 1-6 (1998).

13. Robakis,T., Bak,B., Lin,S.H., Bernard,D.J., \& Scheiffele,P. An internal signal sequence directs intramembrane proteolysis of a cellular immunoglobulin domain protein. J. Biol. Chem. 283, 36369-36376 (2008). 
14. Su,A.l. et al. A gene atlas of the mouse and human protein-encoding transcriptomes. Proc. Natl. Acad. Sci. U. S. A 101, 6062-6067 (2004).

15. Chong,H. et al. Structure and expression of a membrane component of the inhibin receptor system. Endocrinology 141, 2600-2607 (2000).

16. Bernard,D.J. \& Woodruff,T.K. Inhibin binding protein in rats: alternative transcripts and regulation in the pituitary across the estrous cycle. Mol. Endocrinol 15, 654-667 (2001).

17. Bernard,D.J., Burns,K.H., Haupt,B., Matzuk,M.M., \& Woodruff,T.K. Normal reproductive function in InhBP/p120-deficient mice. Mol. Cell Biol. 23, 4882-4891 (2003).

18. Chapman,S.C. \& Woodruff,T.K. Modulation of activin signal transduction by inhibin B and inhibin-binding protein (INhBP). Mol. Endocrinol 15, 668-679 (2001).

19. Chapman,S.C., Bernard,D.J., Jelen,J., \& Woodruff,T.K. Properties of inhibin binding to betaglycan, InhBP/p120 and the activin type II receptors. Mol. Cell Endocrinol 196, 79-93 (2002).

20. Razvi,S. et al. The beneficial effect of L-thyroxine on cardiovascular risk factors, endothelial function, and quality of life in subclinical hypothyroidism: randomized, crossover trial. J. Clin. Endocrinol. Metab 92, 1715-1723 (2007).

21. Singh,S. et al. Impact of subclinical thyroid disorders on coronary heart disease, cardiovascular and all-cause mortality: a meta-analysis. Int. J. Cardiol. 125, 41-48 (2008).

22. Doin,F.C., Rosa-Borges,M., Martins,M.R., Moises,V.A., \& Abucham,J. Diagnosis of subclinical central hypothyroidism in patients with hypothalamic-pituitary disease by Doppler echocardiography. Eur. J Endocrinol 166, 631-640 (2012).

23. Fredriks,A.M. et al. Continuing positive secular growth change in The Netherlands 1955-1997. Pediatr. Res. 47, 316-323 (2000).

24. Freeman,J.V. et al. Cross sectional stature and weight reference curves for the UK, 1990. Arch Dis Child 73, 17-24 (1995).

25. Cacciari,E. et al. Italian cross-sectional growth charts for height, weight and BMI (2 to 20 yr). J Endocrinol Invest 29, 581-593 (2006).

26. Cole,T.J. \& Roede,M.J. Centiles of body mass index for Dutch children aged 0-20 years in 1980--a baseline to assess recent trends in obesity. Ann. Hum. Biol. 26, 303-308 (1999).

27. Van Schnakenburg,K., Bidlingmaier,F., \& Knorr,D. 17-Hydroxyprogesterone, androstenedione, and testosterone in normal children and in prepubertal patients with congenital adrenal hyperplasia. Eur. J. Pediatr. 133, 259-267 (1980).

28. Li,H. \& Durbin, R. Fast and accurate short read alignment with Burrows-Wheeler transform. Bioinformatics. 25, 1754-1760 (2009).

29. Li,H. et al. The Sequence Alignment/Map format and SAMtools. Bioinformatics. 25, 2078-2079 (2009). 
30.

Wu,T.D. \& Nacu,S. Fast and SNP-tolerant detection of complex variants and splicing in short reads. Bioinformatics. 26, 873-881 (2010).

31. McKenna,A. et al. The Genome Analysis Toolkit: a MapReduce framework for analyzing next-generation DNA sequencing data. Genome Res 20, 1297-1303 (2010).

32. Bernard,D.J. Both SMAD2 and SMAD3 mediate activin-stimulated expression of the follicle-stimulating hormone beta subunit in mouse gonadotrope cells. Mol. Endocrinol 18, 606-623 (2004).

33. Lanctot,C., Gauthier,Y., \& Drouin,J. Pituitary homeobox 1 (Ptx1) is differentially expressed during pituitary development. Endocrinology 140, 1416-1422 (1999).

34. Gaston-Massuet,C. et al. Increased Wingless (Wnt) signaling in pituitary progenitor/stem cells gives rise to pituitary tumors in mice and humans. Proc. Natl. Acad. Sci. U. S. A 108, 11482-11487 (2011).

35. Siemensma,E.P., de Lind van Wijngaarden RF, Otten,B.J., de Jong,F.H., \& HokkenKoelega,A.C. Testicular failure in boys with Prader-Willi syndrome: longitudinal studies of reproductive hormones. J Clin Endocrinol Metab 97, E452-E459 (2012).

36. Kevenaar,M.E. et al. Variants in the ACVR1 gene are associated with AMH levels in women with polycystic ovary syndrome. Hum. Reprod. 24, 241-249 (2009).

37. McGuinness, L. et al. Autosomal dominant growth hormone deficiency disrupts secretory vesicles in vitro and in vivo in transgenic mice. Endocrinology 144, 720-731 (2003).

38. Pohlenz,J. et al. Improved radioimmunoassay for measurement of mouse thyrotropin in serum: strain differences in thyrotropin concentration and thyrotroph sensitivity to thyroid hormone. Thyroid 9, 1265-1271 (1999).

39. Weiss, R.E. et al. Mice deficient in the steroid receptor co-activator 1 (SRC-1) are resistant to thyroid hormone. EMBO J 18, 1900-1904 (1999).

40. Paxinos,G. \& Franklin,K.B.J. The Mouse Brain in Stereotaxic Coordinates . Second edition. 2001. Academic Press.

41. VanGuilder,H.D., Vrana,K.E., \& Freeman,W.M. Twenty-five years of quantitative PCR for gene expression analysis. BioTechniques 44, 619-626 (2008).

42. Livak,K.J. \& Schmittgen,T.D. Analysis of relative gene expression data using real-time quantitative PCR and the 2(-Delta Delta C(T)) Method. Methods 25, 402-408 (2001). 
Loss-of-function mutations in IGSF1 cause an X-linked syndrome of central hypothyroidism and testicular enlargement.

Yu Sun, Beata Bak, Nadia Schoenmakers, A.S. Paul van Trotsenburg, Wilma Oostdijk, Peter Voshol, Emma Cambridge, Jacqueline K. White, Paul le Tissier, S. Neda Mousavy Gharavy, Juan P. Martinez-Barbera, Wilhelmina H. Stokvis-Brantsma, Thomas Vulsma, Marlies J. Kempers, Luca Persani, Irene Campi, Marco Bonomi, Paolo Beck-Peccoz, Hongdong Zhu, Timothy M.E. Davis, Anita C.S. Hokken-Koelega, Daria Gorbenko Del Blanco, Jayanti J. Rangasami, Claudia A.L. Ruivenkamp, Jeroen F.J. Laros, Marjolein Kriek, Sarina G. Kant, Cathy A.J. Bosch,Nienke R. Biermasz, Natasha M. Appelman-Dijkstra, Eleonora P. Corssmit, Guido C.J.Hovens, Alberto M. Pereira, Johan T. den Dunnen, Michael G. Wade, Martijn H. Breuning, Raoul C. Hennekam, Krishna Chatterjee, Mehul T. Dattani, Jan M. Wit, Daniel J. Bernard

\section{Supplementary information}


Family C

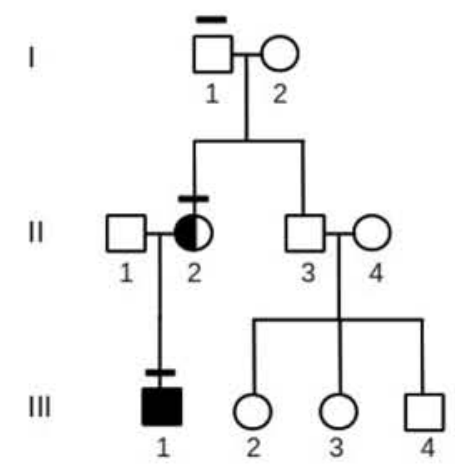

Family E

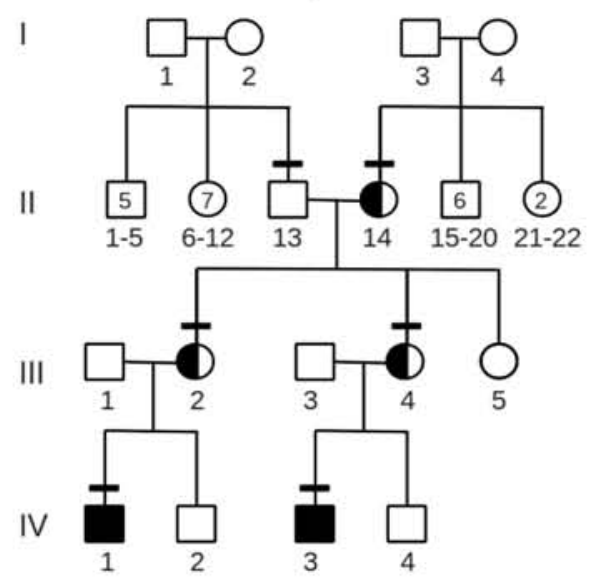

Family G

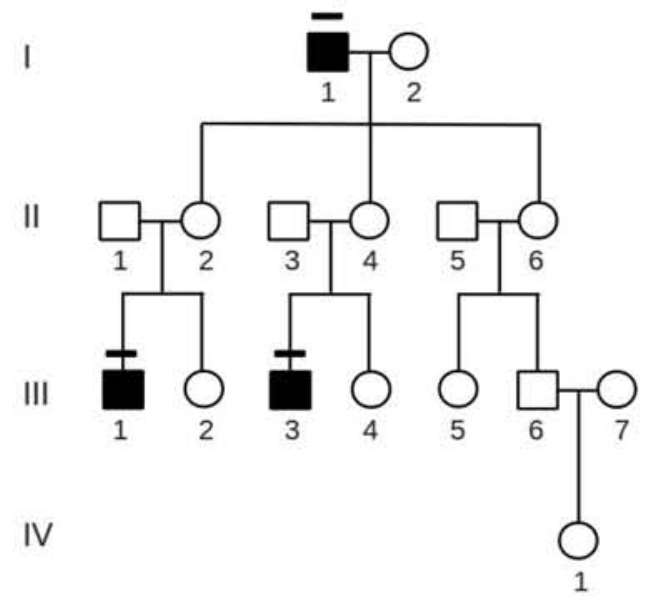

Family I

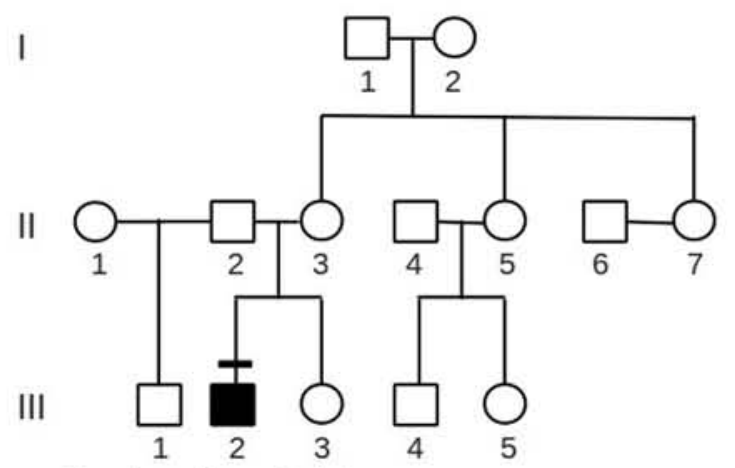

Family D

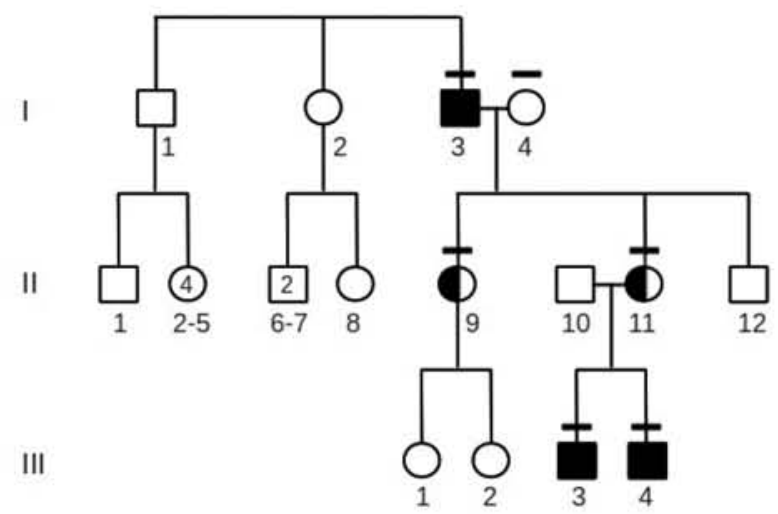

Family $\mathrm{F}$

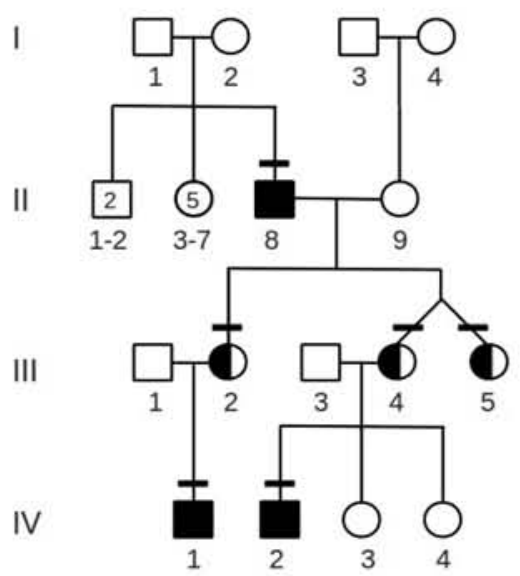

Family $\mathrm{H}$

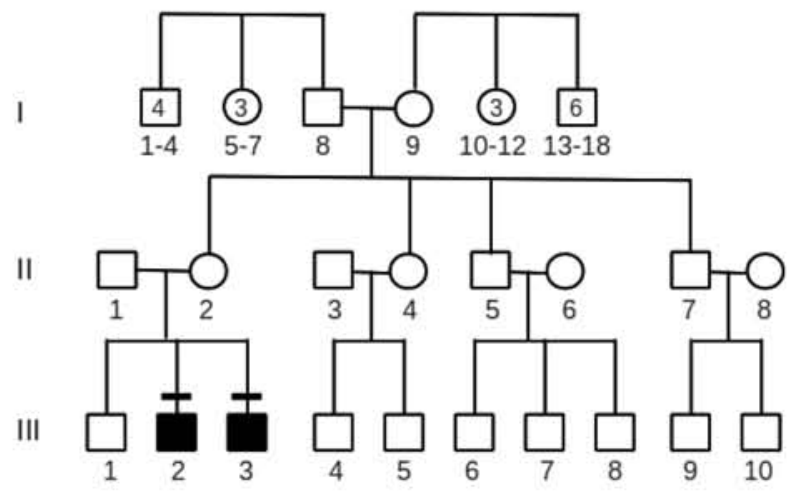

Family J

Family $\mathrm{K}$
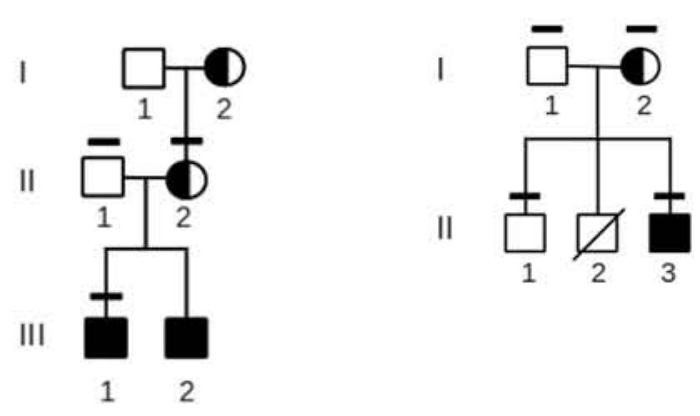


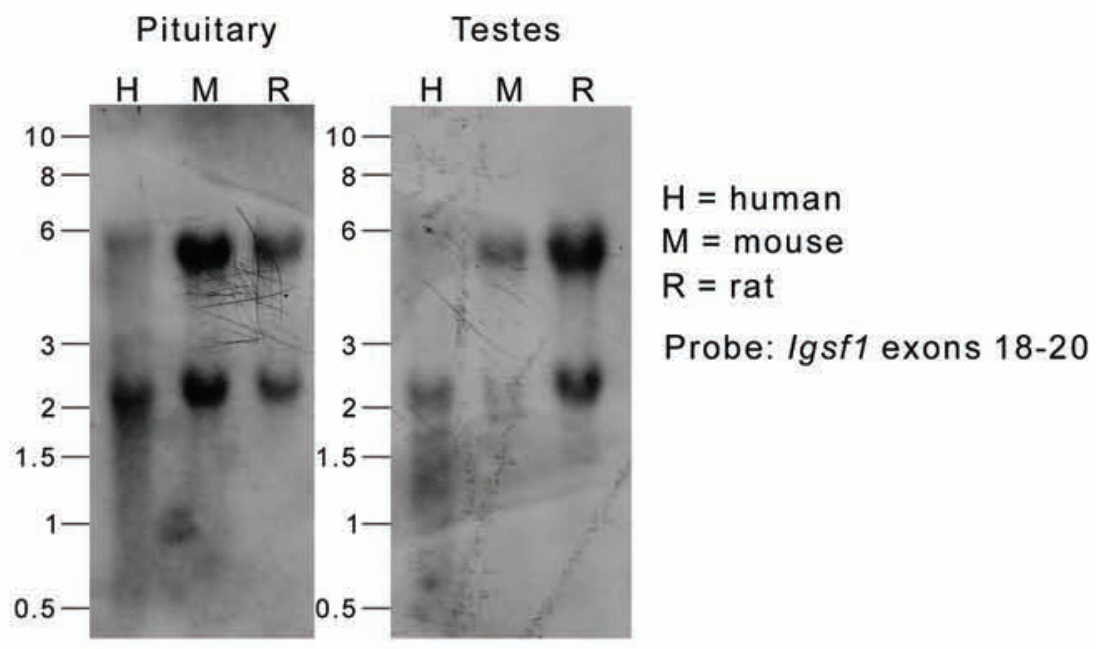

Northern blot comparing IGSF1/lgsf1 expression

Northern blot comparing IGSF1/lgsf1 expression in adult human (H), murine (M), and rat $(R)$ pituitary and testes. Probe was directed against the 3 ' end of murine Igsf1. 

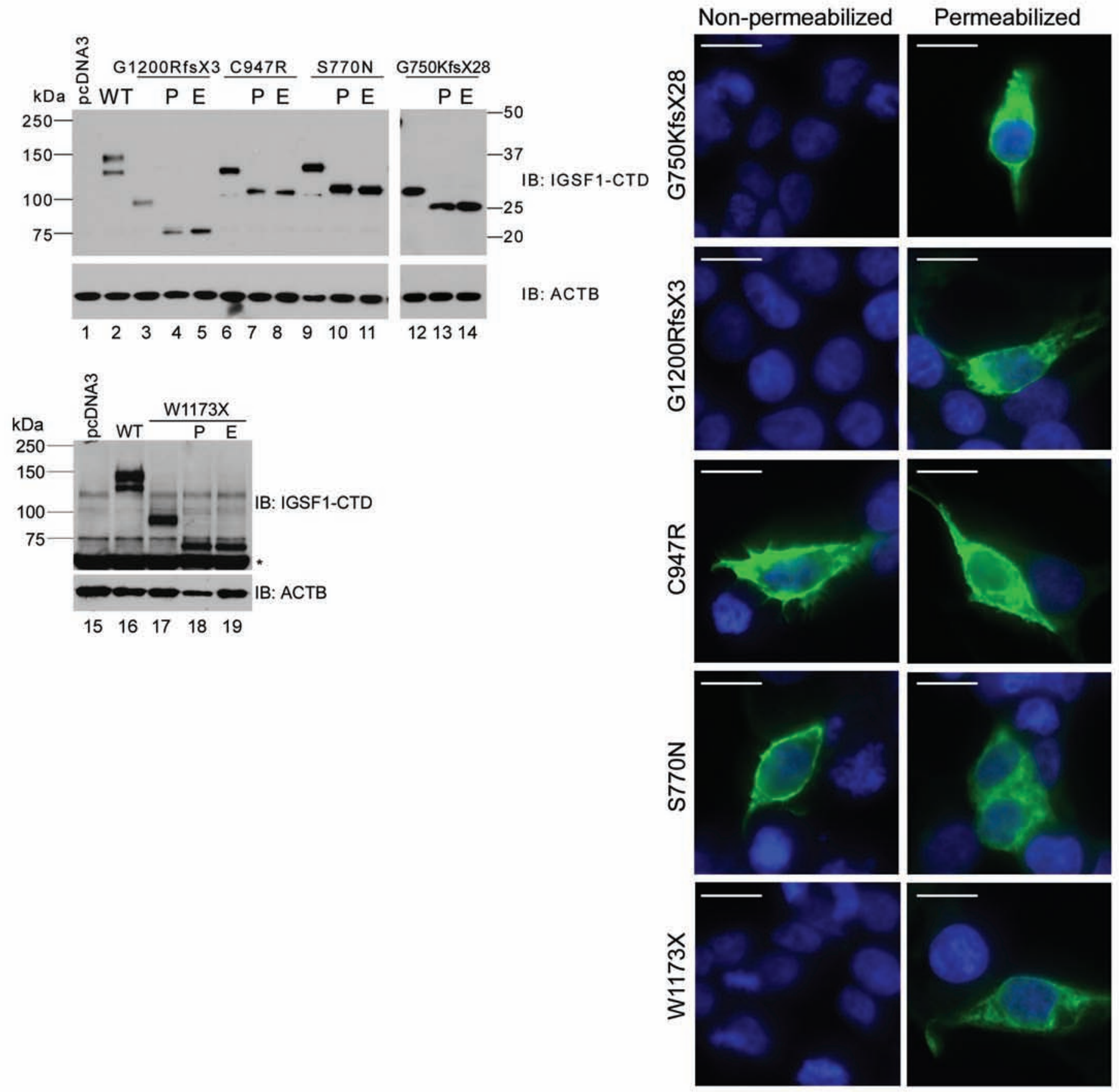

\section{Expression of additional IGSF1 mutants}

(a) HEK293 cells were transfected with $200 \mathrm{ng}$ of pcDNA3 (empty vector), wild-type hIGSF1 or mutant (Glu750LysfsX28, Glu1200ArgfsX3, Cys947Arg, Ser770Asn and Trp1173X) constructs.

Protein lysates were deglycosylated with either PNGaseF ( $P$, cleaves all $N$-linked glycans) or

EndoH (E, cleaves high-mannose glycans only), run on SDS-PAGE, and subjected to immunoblotting using alGSF1-CTD antibody. (b) HEK293 cells were transfected with $100 \mathrm{ng}$ of pcDNA3 (empty vector), wild-type IGSF1 or mutant (Glu750LysfsX28, Glu1200ArgfsX3, Cys947Arg, Ser770Asn, and Trp1173X) expression constructs. Expression of IGSF1-CTD was analyzed by immunofluorescence using aIGSF1-CTD antibody under non-permeabilizing and permeabilizing conditions. Nuclei are stained with DAPI (blue). Scale bars, $10 \mu \mathrm{m}$. 
a

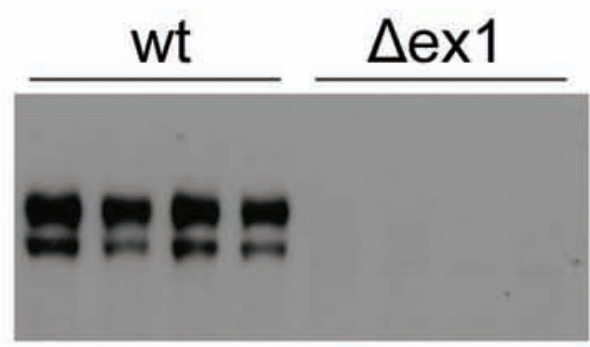

IB: IGSF1-CTD

IB: ACTB b WT

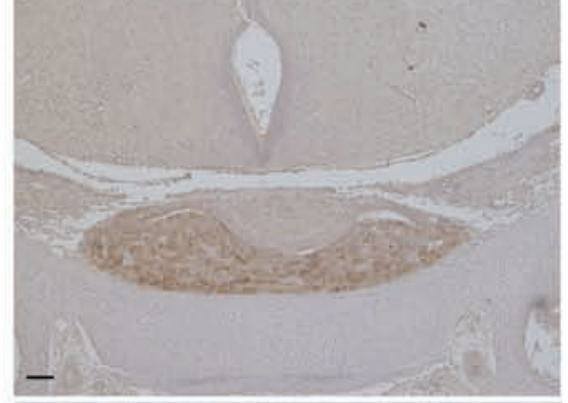

\section{$\Delta \mathrm{ex} 1$}

IGSF1-CTD expression in wild-type vs. Igsf1-deficient mice

(a) IGSF1-CTD protein is undetectable in pituitaries of Igsf1 $\mathrm{ex} 1 \mathrm{mice}$. Protein lysates from individual pituitaries of adult wild-type and Igsf1 1 ex1male mice were run on SDS-PAGE and subject to western blotting using IGSF1-CTD antiserum. (b) Immunohistochemistry for IGSF1 in WT and Igsf1 $\Delta$ ex1male mice pituitary at embryonic day 18.5. Scale bars, $10 \mu \mathrm{m}$. 
a

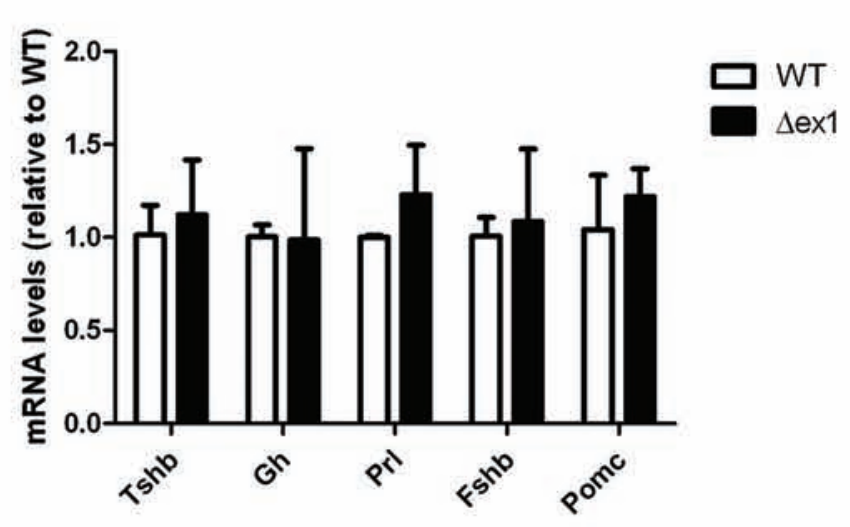

C

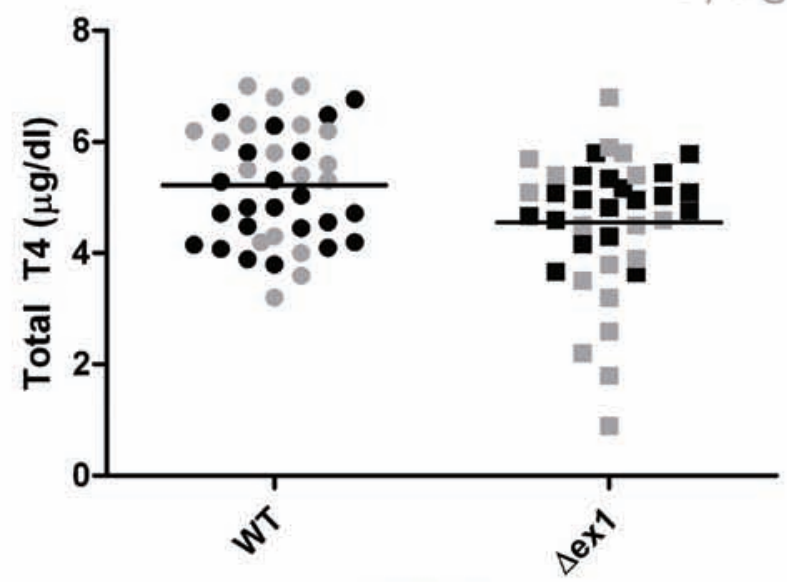

Genotype b

$\bullet / \cdot$ Set 1

$\cdot /$ Set 2
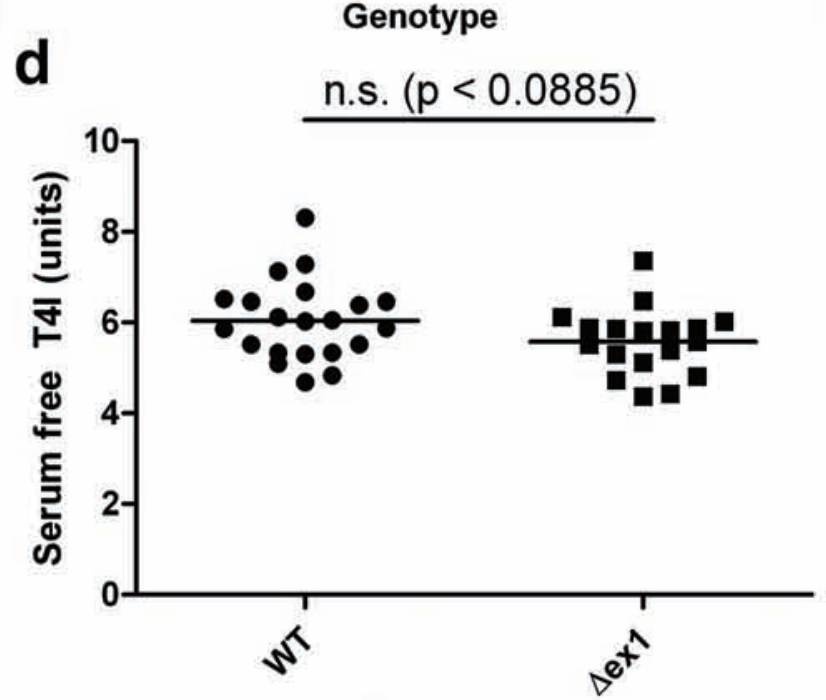

Genotype

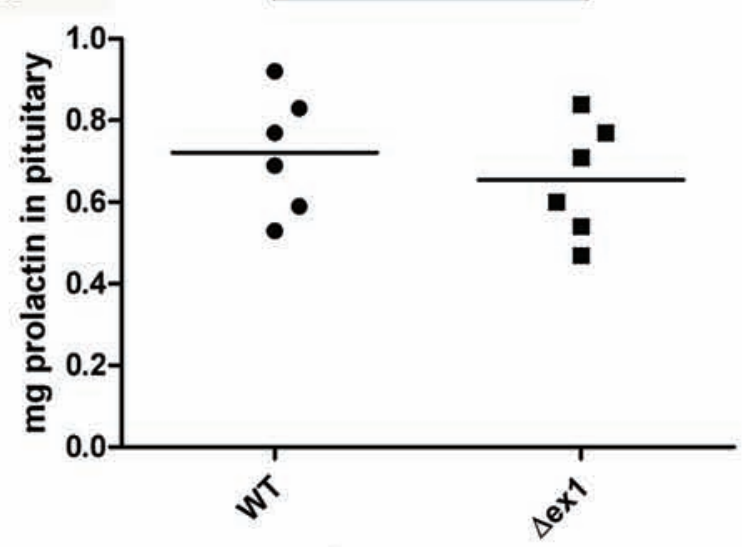

Genotype

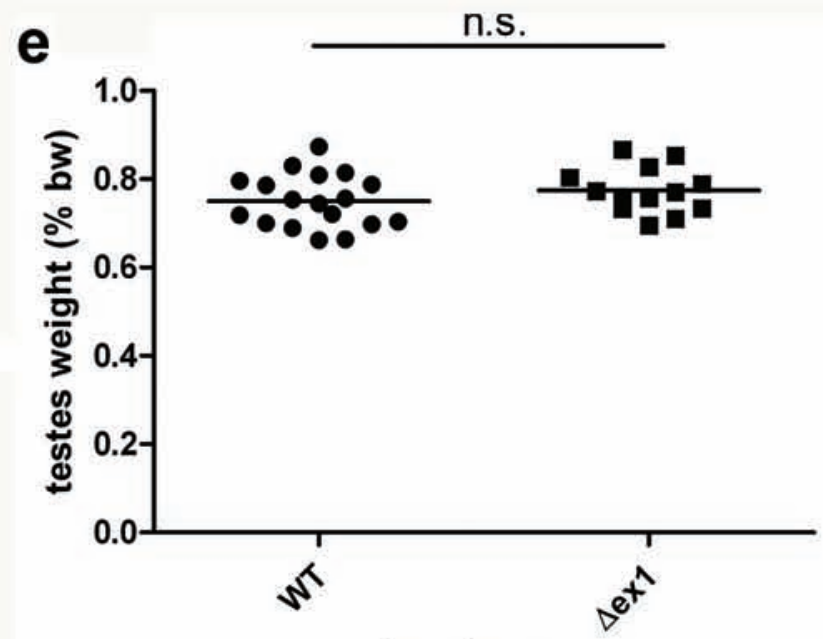

\section{Genotype}

Hormone expression data and testes size in wild-type vs. Igsf1-deficient mice

(a) mRNA levels of anterior pituitary hormone encoding genes do not differ between adult wild-type and Igsf1 $\triangle \mathrm{ex} 1$ male mice. RNA was extracted from pools of 3 pituitaries (2 pools per genotype), reversetranscribed, and qPCR performed using primers against Tshb - thyroid-stimulating hormone $\beta$ subunit; $\mathrm{Gh}$ - growth hormone; $\mathrm{Prl}$ - prolactin; Fshb - follicle-stimulating hormone $\beta$ subunit; Pomc proopiomelanocortin. Data indicate mean \pm s.e.m., relative to wild-type for each hormone. (b) Pituitary prolactin content does not differ between adult male wild-type and Igsf1 1 ex1 mice. (c) Serum (set 1) or plasma (set 2) total T4 was measured in two different sets of animals, using two different assays. Samples from each set are indicated in black or gray. Statistics: set 1: n.s. $(p<0.6133)$; set 2: $p<0.0094$; set $1+$ set $2: p<0.0117$. (d) Serum free T4 was measured in adult wild-type and Igsf1 $\Delta$ ex1 mice. (e) Testes weights (as a percentage of body weight) do not differ between adult male wild-type and Igsf1 $1 \mathrm{ex} 1$ mice. 
Supplementary Table 1. Overview of exome sequencing data

\begin{tabular}{|l|l|l|l|l|}
\hline Patient & A-III.11 & A-III.7 & B-III.7 & B-III.8 \\
\hline Total reads & $15,039,708$ & $13,712,350$ & $83,312,890$ & $83,457,089$ \\
\hline Platform & GAII, Illumina & GAII, Illumina & $\begin{array}{l}\text { SOLiD 4, Applied } \\
\text { Biosystem }\end{array}$ & $\begin{array}{l}\text { SOLiD 4, Applied } \\
\text { Biosystem }\end{array}$ \\
\hline Read length & 51 nt, paired end & 51 nt, paired end & 50nt, single end & 50 nt, single end \\
\hline Aligned reads & $14,865,896$ & $13,554,229$ & $51,718,911$ & $46,780,793$ \\
\hline PCT_aligned_reads & $98.84 \%$ & $98.85 \%$ & $62.08 \%$ & $56.05 \%$ \\
\hline Capture kit & $\begin{array}{l}\text { SureSelect Human } \\
\text { X-exome }\end{array}$ & $\begin{array}{l}\text { SureSelect Human } \\
\text { X-exome }\end{array}$ & $\begin{array}{l}\text { SureSelect Human } \\
\text { All exon 50MB }\end{array}$ & $\begin{array}{l}\text { SureSelect Human } \\
\text { All exon 50MB }\end{array}$ \\
\hline PERCENT_DUPLICATION & $29.20 \%$ & $21.10 \%$ & $44.59 \%$ & $44.36 \%$ \\
\hline MEAN_BAIT_COVERAGE & 76.80 & 73.83 & 17.34 & 15.55 \\
\hline ZERO_CVG_TARGETS_PCT & $4.87 \%$ & $4.95 \%$ & $9.89 \%$ & $7.28 \%$ \\
\hline PCT_TARGET_BASES_10X & $92.58 \%$ & $91.85 \%$ & $58.0 \%$ \\
\hline
\end{tabular}


Supplementary Table 2. Thyroid function test results at diagnosis

\begin{tabular}{l|l|l|l|l|l|}
\hline Case & Age & $\begin{array}{l}\text { TSH } \\
\text { (mU/L) }\end{array}$ & $\begin{array}{l}\text { Free T4 } \\
(\% \text { LL) }\end{array}$ & $\begin{array}{l}\text { T3 } \\
(\% \text { LL) }\end{array}$ & $\begin{array}{l}\text { TSH (mU/L) response } \\
\text { to TRH (TSH at } \\
\text { baseline; 20 minutes) }\end{array}$ \\
\hline A-III.11 & 3 wks & 3.5 & 69.2 & 100.0 & $2.6 ; 10.4$ \\
\hline$A-I I I .7$ & 7.3 yrs & 1.6 & 88.0 & & $0.5 ; 4.3$ \\
\hline$A-I I .4$ & 52.4 yrs & 0.8 & 94.0 & 130.8 & $0.6 ; 4.7$ \\
\hline$A-I .4$ & 74 yrs & 0.9 & 90.0 & 145.4 & \\
\hline$B-I I I .7$ & 4 wks & 1.8 & 79.6 & & \\
\hline$B-I I I .8$ & 7 wks & 2.6 & 46.7 & & \\
\hline$B-I I .11$ & 43.3 yrs & 1.7 & 80.0 & $150.0^{3}$ & $1.7 ; 7.6$ \\
\hline$B-I .4$ & 65.9 yrs & 1.7 & 91.0 & 126.9 & $1.7 ; 4.5$ \\
\hline$C-I I I .1$ & 3 wks & 1.4 & 86.7 & 97.6 & $2.3 ; 7.8$ \\
\hline$D-I I .3$ & 3 wks & 4.8 & 42.5 & & $4.6 ; 8.4$ \\
\hline$D-I I I .4$ & 1 wk & 2.9 & 80.0 & 87.5 & \\
\hline$D-I .3$ & 61 yrs & 2.9 & 85.0 & 118.2 & $2.2 ; 6.6$ \\
\hline$E-I V .1$ & 2 wks & 5.6 & 75.0 & 83.3 & $3.0 ; 8.4$ \\
\hline$E-I V .3$ & 2.5 wks & 3.7 & 81.7 & 100.0 & $2.8 ; 9.9$ \\
\hline$F-I V .1$ & 3 wks & 4.2 & 60.8 & & \\
\hline$F-I V .2$ & 3 wks & 1.5 & 78.3 & & \\
\hline$F-I I .8$ & 57.5 yrs & 3.0 & 95.0 & 190.9 & $2.3 ; 8.5$ \\
\hline$G-I I I .1$ & 5 wks & 1.1 & 84.2 & & $1.1 ; 4.5$ \\
\hline$G-I I I .3$ & 2.5 wks & 2.2 & 66.7 & 108.3 & $2.2 ; 16$ \\
\hline$G-I .1$ & 63 yrs & 1.2 & $88.3^{2}$ & & $1.2 ; 5.7$ \\
\hline$H-I I I .2$ & 6.5 yrs & 3.6 & 80.0 & & \\
\hline$H-I I I .3$ & 3 wks & 6.0 & 83.3 & 120.9 & $6.3 ; 10.6$ \\
\hline$I-I I I .2$ & 14,1 yrs & 0.95 & 89.0 & & \\
\hline$J-I I I .1$ & 3 wks & 2.5 & 79.1 & $88.9^{3}$ & \\
\hline$J-I I I .2$ & 2 wks & 3.2 & 74.1 & $93.3^{3}$ & \\
\hline$K-I I .3$ & 10.6 yrs & 1.2 & 84.1 & $107.7^{3}$ & $1.2 ; 5.7$ \\
\hline Mean(SD) & & $2.6(1.5)$ & $79(13)$ & $116(28)^{4}$ & \\
\hline & & & & & \\
\hline
\end{tabular}

${ }^{1}$ Reference range for serum TSH: 0.8-6.0 mU/L

${ }^{2}$ Total T4

${ }^{3}$ Free T3

${ }^{4}$ Means (SD) in 1-3 week old infants and older individuals were $98(12) \%$ and $139(27) \%$ of the lower limit (LL) of the reference range for age and assay, respectively 
Supplementary Table 3. TSH, FT4 and FT3 responses to TRH

\begin{tabular}{|c|c|c|c|c|c|c|c|c|c|}
\hline \multirow[t]{2}{*}{ Case } & \multirow[t]{2}{*}{ Age } & \multicolumn{2}{|c|}{ TSH (mU/L) } & \multicolumn{2}{|c|}{ FT4 (pmol/L) } & \multirow[t]{2}{*}{$\Delta \mathrm{FT} 4(\%)$} & \multicolumn{2}{|c|}{ FT3 (pmol/L) } & \multirow[t]{2}{*}{$\triangle \mathrm{FT3}(\%)$} \\
\hline & & 0 & peak & 0 & peak & & 0 & peak & \\
\hline$E-I V .1$ & $2 \mathrm{wk}$ & 3.0 & 8.4 & 8.4 & 9.8 & 16.7 & & & \\
\hline$C-I I I .1$ & $3 w k$ & 2.3 & 7.8 & 9.1 & 9.6 & 5.5 & & & \\
\hline$A-I I I .11$ & $3 w k$ & 2.6 & 10.4 & 8.3 & 9.4 & 13.3 & & & \\
\hline$B-I I .11$ & $43.3 \mathrm{yr}$ & 1.7 & 7.6 & 7.2 & 8.0 & 11.1 & 4.5 & 5.1 & 13.3 \\
\hline$A-I I .4$ & $52.4 \mathrm{yr}$ & 0.6 & 4.7 & 8.8 & 9.8 & 11.4 & 2.9 & 3.9 & 34.5 \\
\hline$F-I I .8$ & $58.2 \mathrm{yr}$ & 2.3 & 8.5 & 8.5 & 10.2 & 20.0 & 3.9 & 6.0 & 53.8 \\
\hline$D-I .3$ & $62.8 \mathrm{yr}$ & 2.2 & 6.6 & 7.3 & 8.0 & 9.6 & 3.2 & 5.6 & 75.0 \\
\hline$B-I .4$ & $65.9 \mathrm{yr}$ & 1.7 & 4.5 & 9.1 & 9.9 & 8.8 & 4.0 & 4.8 & 20.0 \\
\hline$B-I-4^{3}$ & $66.4 \mathrm{yr}$ & 1.3 & 3.8 & 6.6 & 8.7 & 31.8 & 4.3 & 5.2 & 20.9 \\
\hline Mean & & 2.0 & 6.9 & 8.1 & 9.3 & $14.2^{1}$ & 3.8 & 5.1 & $36.3^{2}$ \\
\hline SD & & 0.7 & 2.2 & 0.9 & 0.8 & 7.9 & 0.6 & 0.7 & 26.4 \\
\hline
\end{tabular}

${ }^{1}$ Reference data for FT4 increment: mean (SEM) 23.9 (2.7)\%

${ }^{2}$ Reference data for FT3 increment: mean (SEM) 41.8 (4.5)\%

${ }^{3}$ In this subject, the TRH test was repeated 
Supplementary Table 4. Primers used to amplify and sequence the IGSF1 gene in patients in families $A$ and $C$ to I (Leiden)

\begin{tabular}{|c|c|c|c|}
\hline PrimerID_lab & Sequence(5'-3') & $\begin{array}{l}\text { Product } \\
\text { size(bp) }\end{array}$ & $\begin{array}{c}\text { Covered range } \\
\text { NM_001170961.1 }\end{array}$ \\
\hline IGSF1_1a_F & GCGCTTTTTCCAGTTTCAAAG & \multirow{2}{*}{549} & \multirow{2}{*}{ Exon 20 utr } \\
\hline IGSF1_1a_R & GAGCTGGGTAAAGGGGATTC & & \\
\hline IGSF1_1b_F & TTCATGCGCCAGTAAATCAG & \multirow{2}{*}{581} & \multirow{2}{*}{ Exon 20} \\
\hline IGSF1_1b_R & TGTTGTAGCCTTGGGGGTAG & & \\
\hline IGSF1_2_F & САСTCTTCAAGGGCAATGGT & \multirow{2}{*}{406} & \multirow{2}{*}{ Exon 19} \\
\hline IGSF1_2_R & AGAGTGTGGGGCAATACCAG & & \\
\hline IGSF1_3_F & TCCTGATTTGGGATGTCTCC & \multirow{2}{*}{511} & \multirow{2}{*}{ Exon 18} \\
\hline IGSF1_3_R & GTGACTCCCTGGAGATCTGG & & \\
\hline IGSF1_4_F & GGTTTAGGGGGCTTATCTGC & \multirow{2}{*}{541} & \multirow{2}{*}{ Exon 17} \\
\hline IGSF1_4_R & TCAGAGAGCTCGAGGAGAGG & & \\
\hline IGSF1_5_F & СCTGGGGTCTCTGCTCAATA & \multirow{2}{*}{521} & \multirow{2}{*}{ Exon 16} \\
\hline IGSF1_5_R & AACTACCGTGCCCAAGAGG & & \\
\hline IGSF1_6_F & CCATGGCTTAGGGAATGTGT & \multirow{2}{*}{548} & \multirow{2}{*}{ Exon 15} \\
\hline IGSF1_6_R & TGTGAGGGCTGGGTTTATCT & & \\
\hline IGSF1_7_t_F_2 & GTGCATCATGGACTGGTCAC & \multirow{2}{*}{553} & \multirow{2}{*}{ Exon 14} \\
\hline IGSF1_-̄7_- & AGAAGCCTCCGAGAACCAAT & & \\
\hline IGSF1_8_F & CCTGCCTGGCTCTAAGATTG & \multirow{2}{*}{476} & \multirow{2}{*}{ Exon 13} \\
\hline IGSF1_8_R & GTATCCCATCTGGGCAACTG & & \\
\hline IGSF1_9_F & СTCACTCCCAGGAGCAGTGT & \multirow[b]{2}{*}{492} & \multirow{2}{*}{ Exon 12} \\
\hline IGSF1_9'- $\bar{R} \_2$ & TTCCTCCAAGCTTCTGCACT & & \\
\hline IGSF1_10_11_F_2 & TGCAGAAGCTTGGAGGAAAT & \multirow{2}{*}{573} & \multirow{2}{*}{ Exon 10 , exon 11} \\
\hline IGSF1_10_11 $1 \bar{R}$ & TGGTAAGGCCCTCAAAAAGA & & \\
\hline IGSF1_12_F_2 & GAGACAGGTGGGGTGAGAAA & \multirow{2}{*}{507} & \multirow{2}{*}{ Exon 9} \\
\hline IGSF1_12_R & AGATTGTCCTCACCCCATGA & & \\
\hline IGSF1_13_F & CCTGCTAACTGCCTTTGAGG & \multirow{2}{*}{510} & \multirow{2}{*}{ Exon 8} \\
\hline IGSF1_13_R_2 & CCAAGTGGAAGTGGAAAGGA & & \\
\hline IGSF1_14 $\overline{4}$ F & GGAACAATCCTGGGAGACAA & & \\
\hline IGSF1_14__R_2 & TTAAGGAGTGGGAGCAGGAA & 547 & Exon 7 \\
\hline IGSF1_15_F_2 & AAACCACCCTTGGAAAAACC & & \\
\hline IGSF1_15_- $\bar{R}$ & CCAAGGAAGGGATAGGGAAG & 577 & Exon 6 \\
\hline IGSF1_16a_F & TCTCCGCTAGCAAAAAGCTC & 549 & Exon 5 utr of \\
\hline IGSF1_16a_R & GAATTGGCCACATTTGCTTT & 549 & NM_001170963.1 \\
\hline IGSF1_16b_F & AGGAAGCCAAAGCACAGAAA & & Exon 5 utr of \\
\hline IGSF1_16b_R & AGCAGCTTCAGCTCATCACA & 594 & NM_001170963.1 \\
\hline IGSF1_16c_F & CAACAAAGCTGTGATGAGCTG & & \\
\hline IGSF1_16c_R & СтCTCСTCTGCTGCTCCCTA & 618 & Exon 5 \\
\hline IGSF1_17_F & TTGCATGCATTTGTGAAACA & & \\
\hline IGSF1_17_R & CCCAAGGGAAGACAAAATGA & 493 & Exon 4 \\
\hline IGSF1_18_19_F_2 & ACCATGCCATAGGAAACCAA & 596 & \\
\hline IGSF1_18_19_R & GAGAGGAAGCAGCAGGTGAC & 596 & Exon 2, exon 3 \\
\hline IGSF1_20_21_F & GAGGGTTTGGAGGGAAGACT & & Exon 1 utr, exon 1 utr \\
\hline IGSF1_20_21_R & CTGAATTTGGCTCCAGCAAC & 562 & NM_001170963.1 \\
\hline
\end{tabular}




\section{Supplementary Table 5. Mutagenesis primers for IGSF1 expression plasmids}

\begin{tabular}{|c|c|c|}
\hline Mutation: & Sense Primer: & Antisense Primer: \\
\hline $\begin{array}{l}\text { c.2137_2163del } \\
\text { (p.Ala713_Lys721del) }\end{array}$ & 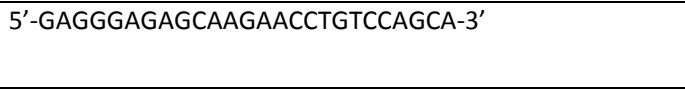 & 5'-CAGCCATCCTTTGCACCGGAGTTGTA-3' \\
\hline $\begin{array}{l}\text { c. } 2931 G>A \\
\text { (p.Trp977X) }\end{array}$ & 5'-ACATTCCCTAAGCCATGATTGTTTGCTGAGCCCAG-3' & 5'-CTGGGCTCAGCAAACAATCATGGCTTAGGGAATGT-3' \\
\hline $\begin{array}{l}\text { c.2248del } \\
\text { (p.Glu750LysfsX28) }\end{array}$ & 5'-GAGAATGGAGGATAAAGACAAGGCAATTACAGCTGCC-3' & 5'-GGCAGCTGTAATTGCCTTGTCTTTATCCTCCATTCTC-3' \\
\hline $\begin{array}{l}\text { c. } 2588 \mathrm{C}>\mathrm{T}, \\
\text { p.(Ser863Phe) }\end{array}$ & 5'-TATTATGACTTTTCTATCTGGTTTGAGCCCAGCGACC-3' & 5'-GGTCGCTGGGCTCAAACCAGATAGAAAAGTCATAATA-3' \\
\hline $\begin{array}{l}\text { c. } 2839 T>C, \\
\text { p.(Cys947Arg) }\end{array}$ & 5'-GGACTCTGGGAACTATAGCCGTATCTACTATGAGACAAC-3' & 5'-GTTGTCTCATAGTAGATACGGCTATAGTTCCCAGAGTCC-3' \\
\hline $\begin{array}{l}\text { c. } 3518 G>A, \\
\text { p. }(\operatorname{Trp} 1173 X)\end{array}$ & 5'-ACCCTCTCTGTCAGCCTAGCCCAGCAC-3' & 5'-GTGCTGGGCTAGGCTGACAGAGAGGGT-3' \\
\hline $\begin{array}{l}\text { c.3596-3597InsT } \\
\text { (p.Glu1200ArgfsX3) }\end{array}$ & 5'-CCAGGTGTTGAATTTGTCCTTAGAACATGATGGAGAAGA-3' & $\begin{array}{l}\text { 5'-TCTTCTCCATCATGTTCTAAGGACAAATTCAACACCTGG-3' } \\
\end{array}$ \\
\hline $\begin{array}{l}\text { c.2309G>A, } \\
\text { p.(Ser770Asn) }\end{array}$ & 5'-GTGGTCTGAGCCCAATGAGCCGCTGGA-3' & 5'-TCCAGCGGCTCATTGGGCTCAGACCAC-3' \\
\hline
\end{tabular}


Supplementary Table 6. Primers used for quantitative RT-PCR in mouse tissues

\begin{tabular}{|c|c|c|}
\hline Gene: & Sense Primer: & Antisense Primer: \\
\hline$T s h b$ & 5'-gaacggtggaaataccagga-3' & 5'-agaaagactgcggcttggtgca-3' \\
\hline Trhr & 5'-ctccccaacataaccgacag-3' & 5'-gcagagaaactgggctttga-3' \\
\hline Fshb & $5^{\prime}$-gtgcgggctactgctacact-3' & 5'-caggcaatcttacggtctcg-3' \\
\hline$G h$ & $5^{\prime}$-acctcggaccgtgtctatga-3' & 5'-gcagcccatagtttttgagc-3' \\
\hline $\mathrm{Prl}$ & 5'-aagcagcttcttgagggagtt-3' & 5'-tgttgcgcaaagacaagatt-3' \\
\hline Pomc & 5'-ccaggaacagcagcagtg-3' & 5'-acgttggggtacaccttcac-3' \\
\hline Trh & 5'- gaaagacctccagcgtgtg-3' & 5'-tcttcggcttcaacgtcttc-3' \\
\hline Rp/19 & 5'-cgggaatccaagaggattga-3' & 5'-ttcagcttgtggatgtgctc-3' \\
\hline
\end{tabular}




\section{Supplementary Note}

After IGSF1 mutations were found in families A and B, all male patients with central hypothyroidism in Leiden, Amsterdam, Rotterdam and Milan of unknown genetic origin were screened for IGSF1 variants, leading to the discovery of IGSF1 mutations in families C through $\mathrm{K}$. At a later stage, full clinical, laboratory and sonographic assessment took place. All participants provided written informed consent.

Four patients showed evidence of growth hormone $(\mathrm{GH})$ insufficiency. Patient A-III.7 was referred for growth failure (height deviation from +2.6 SDS at birth down to -1.4 SDS at 7.3 years). Bone age was three years delayed, serum IGF-I was -1.0 SDS, and GH peaks in clonidine and arginine provocation tests (after correction of hypothyroidism) were 16.9 and $13.1 \mathrm{mU} / \mathrm{L}$ (5.6 and $4.4 \mu \mathrm{g} / \mathrm{L}$ for current standard), respectively. MRI of the brain and pituitary was normal. GH treatment was given from 8.8 to 17.5 years, which led to excellent catch-up growth (from a height of -1.4 to +1.3 SDS), and adult height was even taller than midparental height SDS. After discontinuation of GH treatment, serum IGF-I was between -1.0 and 0 SDS and the insulin tolerance test showed a normal response of $28.7 \mathrm{mU} / \mathrm{L}(9.6 \mu \mathrm{g} / \mathrm{L})$. H-III.3 had GH peaks of 9.5 $\mathrm{mU} / \mathrm{L}(3.2 \mu \mathrm{g} / \mathrm{L})$ and $13 \mathrm{mU} / \mathrm{L}(4.3 \mu \mathrm{g} / \mathrm{L})$ in clonidine and arginine tests and serum IGF-I was -2.0 SDS at a height of -2.1 SDS. GH treatment from 7.5 years onward led to a first year growth velocity of $8.1 \mathrm{~cm} /$ year and an adult height of $-1.6 \mathrm{SDS}$. Brain MRI was normal but the anterior pituitary was relatively small, albeit within the normal range. After $\mathrm{GH}$ discontinuation, serum IGF-I was normal (O SDS) and ATT-GHRH test showed a normal GH peak of $28 \mathrm{mU} / \mathrm{L}(7.3 \mu \mathrm{g} / \mathrm{L})$. Patient I-III.2 was referred for short stature (age 14.1 years, height SDS -2.3 SDS), and had GH peaks after arginine and L-dopa/propranolol tests (after testosterone priming) of 11.6 and 15 $\mathrm{mU} / \mathrm{L}(3.9$ and $5 \mu \mathrm{g} / \mathrm{L}$ ) and a serum IGF-I of $-1.5 \mathrm{SDS}$. His brain MRI was normal and he responded well to GH treatment $(10.9 \mathrm{~cm} / \mathrm{yr}$ in the first year). Patient K-II.3 had a normal GH peak to clonidine stimulation $(11 \mu \mathrm{g} / \mathrm{L})$ at 11.6 years, but low spontaneous $\mathrm{GH}$ secretion in a $12-$ hour nocturnal profile (average $2.26 \mu \mathrm{g} / \mathrm{L}$, reference $>3.5 \mu \mathrm{g} / \mathrm{L}$ ). Serum IGF-I was -0.9 SDS and his brain MRI showed a small pituitary stalk lesion. GH treatment led to adequate catch-up growth

and normal adult height ( $0 \mathrm{SDS}, 8 \mathrm{~cm}$ taller than midparental height SDS). After discontinuation of GH treatment, serum IGF-I, the 12-hour nocturnal profile (average $\mathrm{GH}$ level $4.4 \mathrm{\mu g} / \mathrm{L}$ ) and the $\mathrm{GH}$ peak after $\mathrm{GHRH}$ and arginine $(21.4 \mu \mathrm{g} / \mathrm{L})$ were normal. 
a

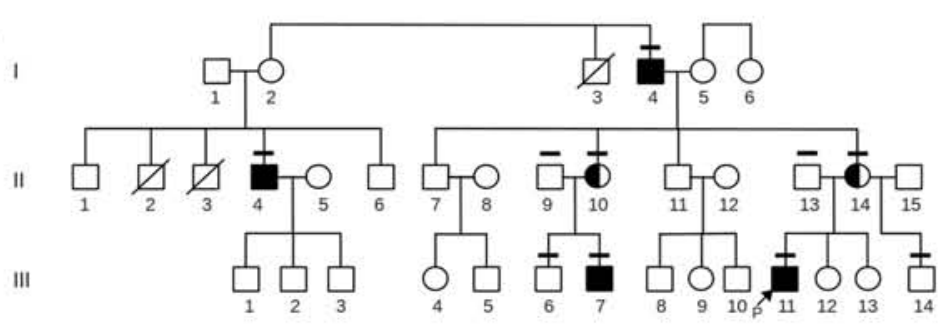

b
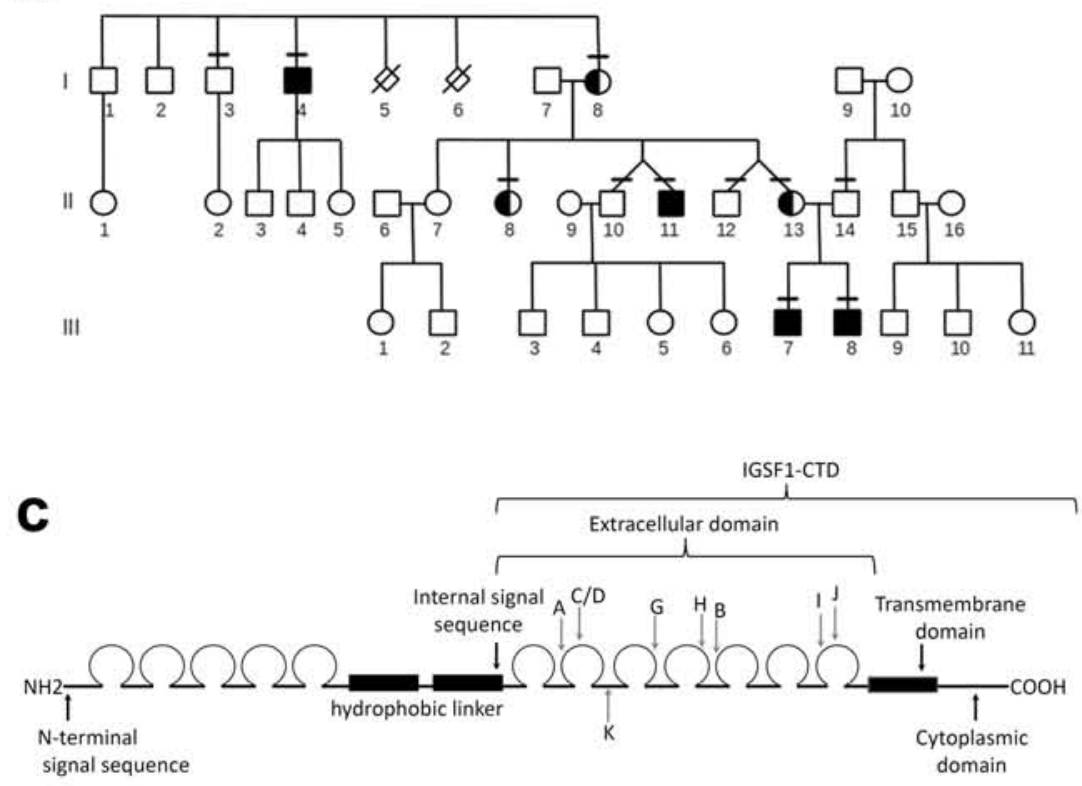

•Family A: c.2137_2163del, p.(Ala713_Lys721del)

-Family B: c.2931G>A, p.(Trp977X)

-Family C \& D: c.2248del, p.(Glu750LysfsX28)

•Family E: 126kb deletion, arr Xq26.1q26.2(130.386.267-130.512.002)x1 (hg19)

-Family F: 328kb deletion, arr Xq26.1q26.2(130.310.905-130.639.353)×1 (hg19)

-Family G: c.2588C $>$ T, p.(Ser863Phe)

-Family H: c.2839T>C, p.(Cys947Arg)

-Family I: c.3518G>A, p.(Trp1173X)

-Family J: c.3596-3597 insT, p.(Glu1200ArgfsX3)

-Family K: c.2309G>A, p.(Ser770Asn) 
a

mouse E12.5 human CS 18 embryo

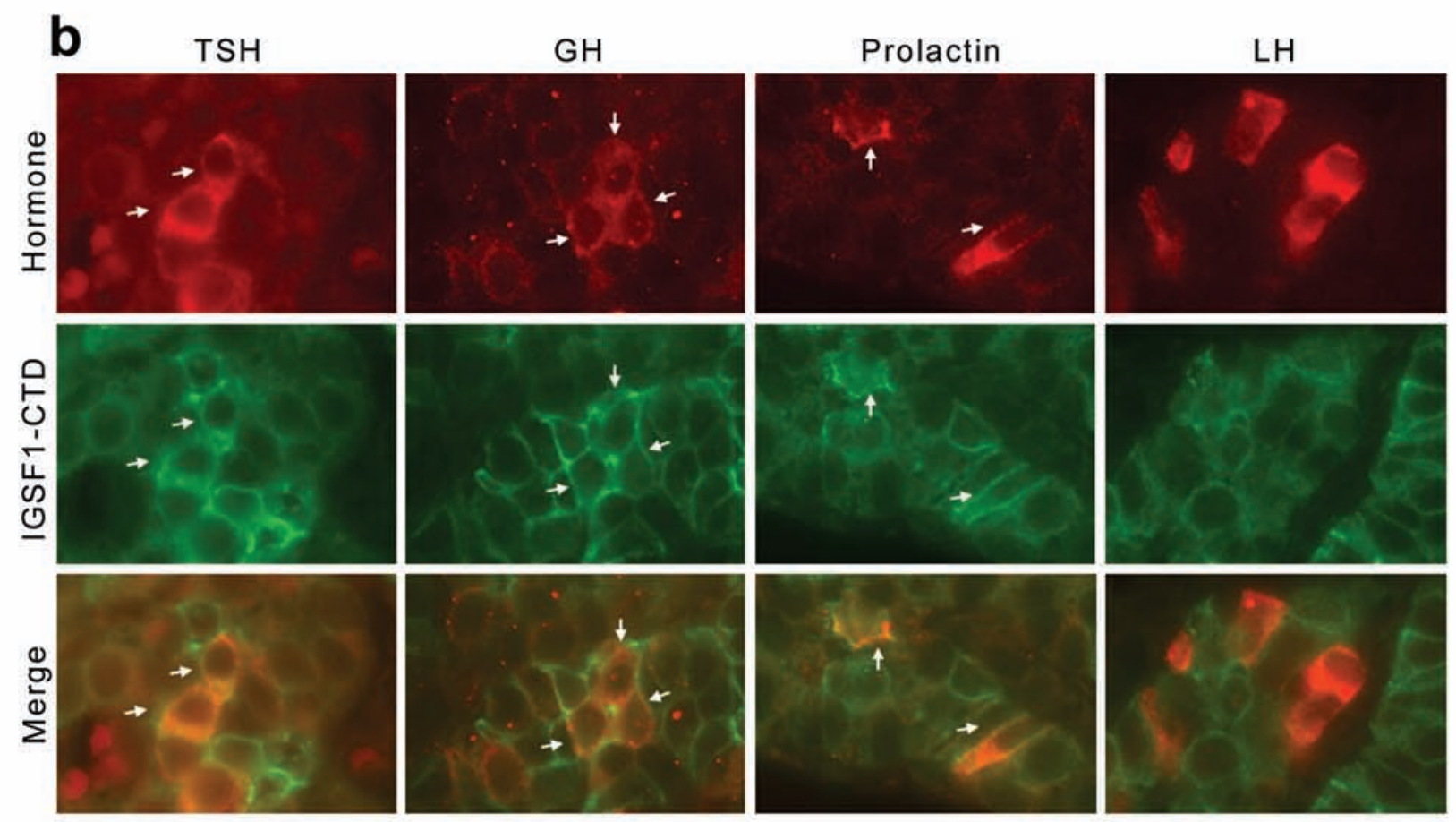

Fig. 2 

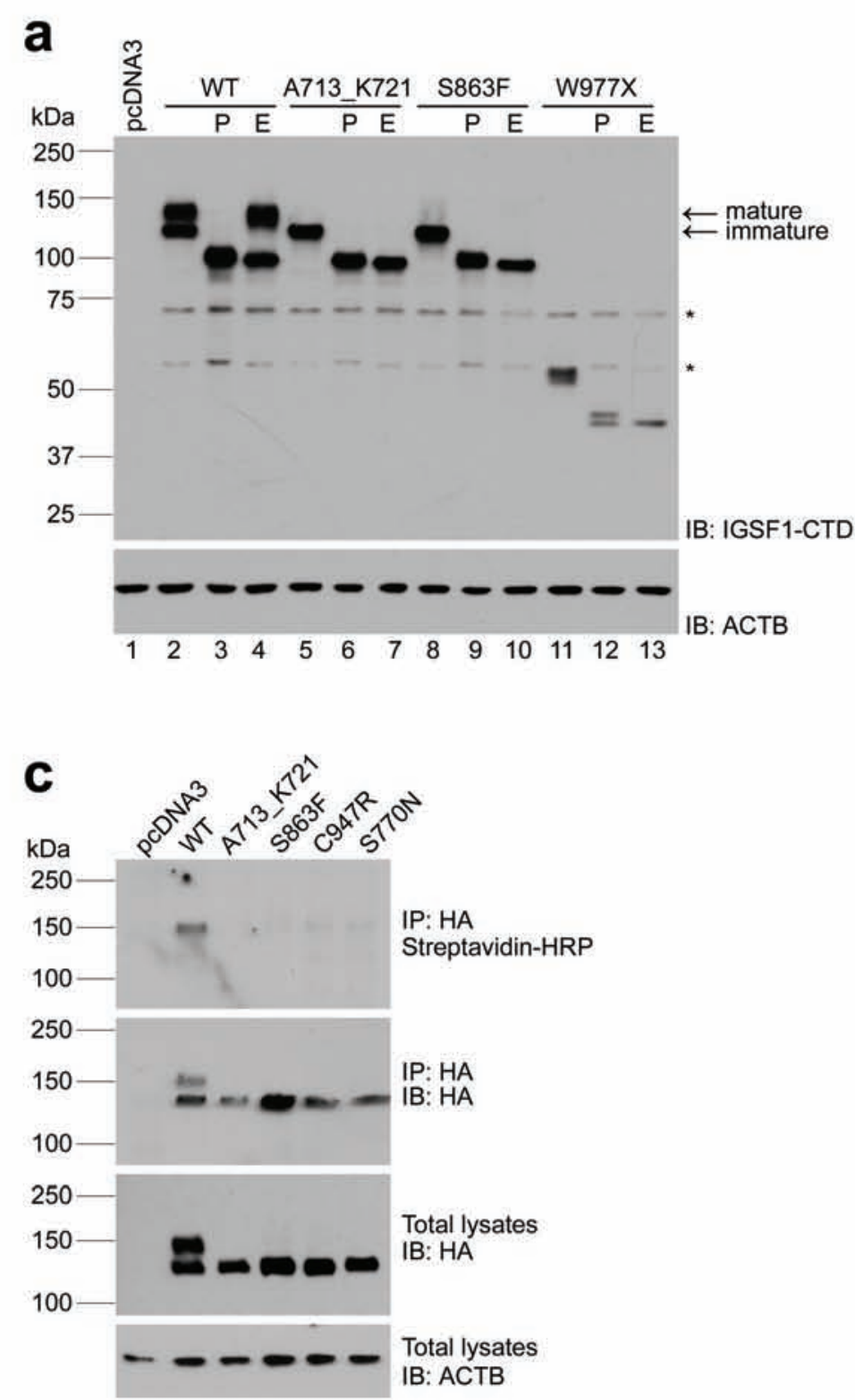

b
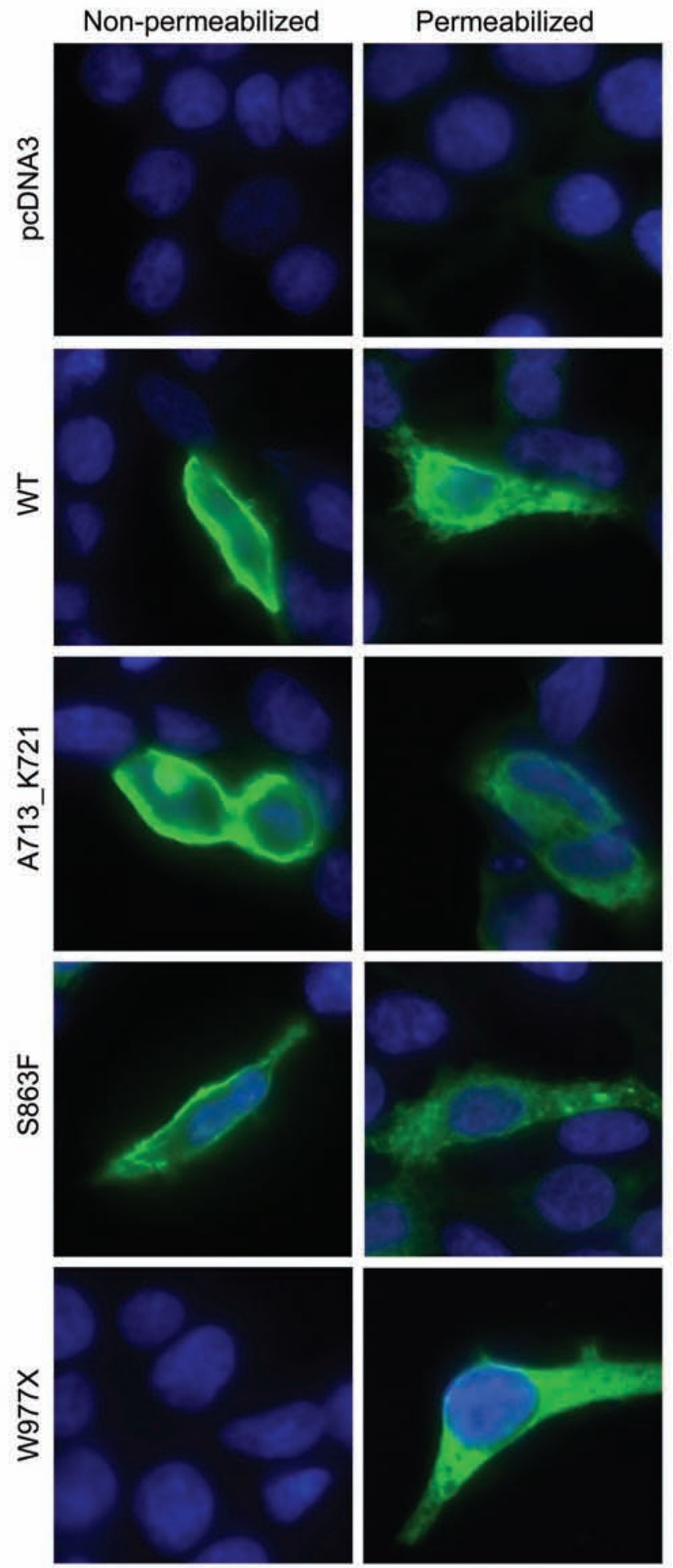

Fig. 3 


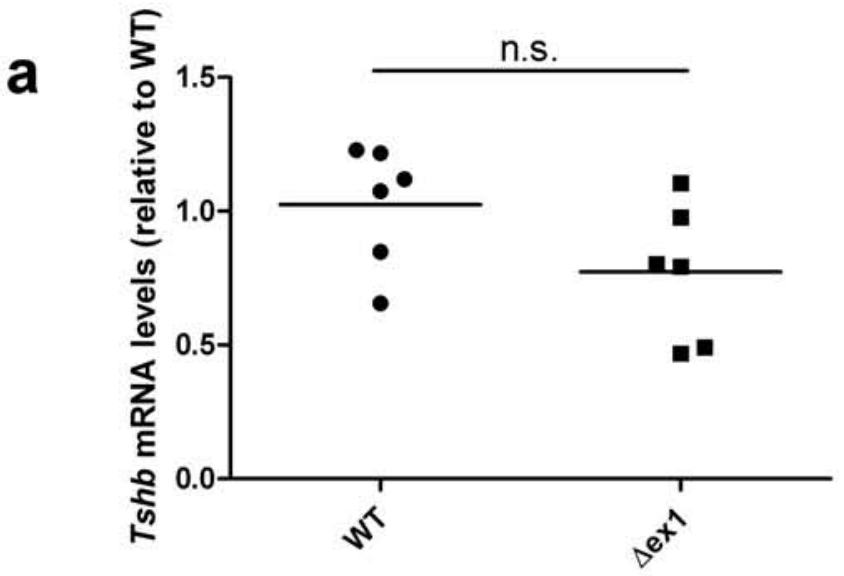

Genotype

C

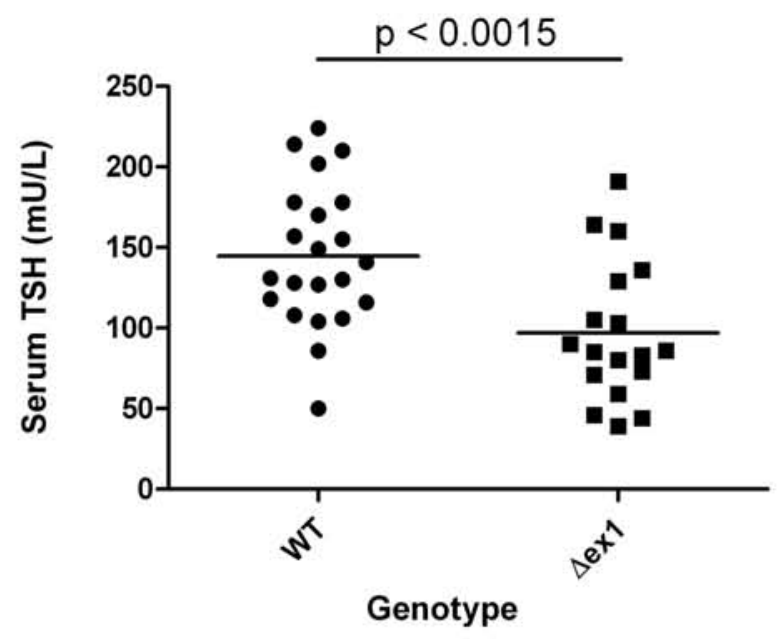

9
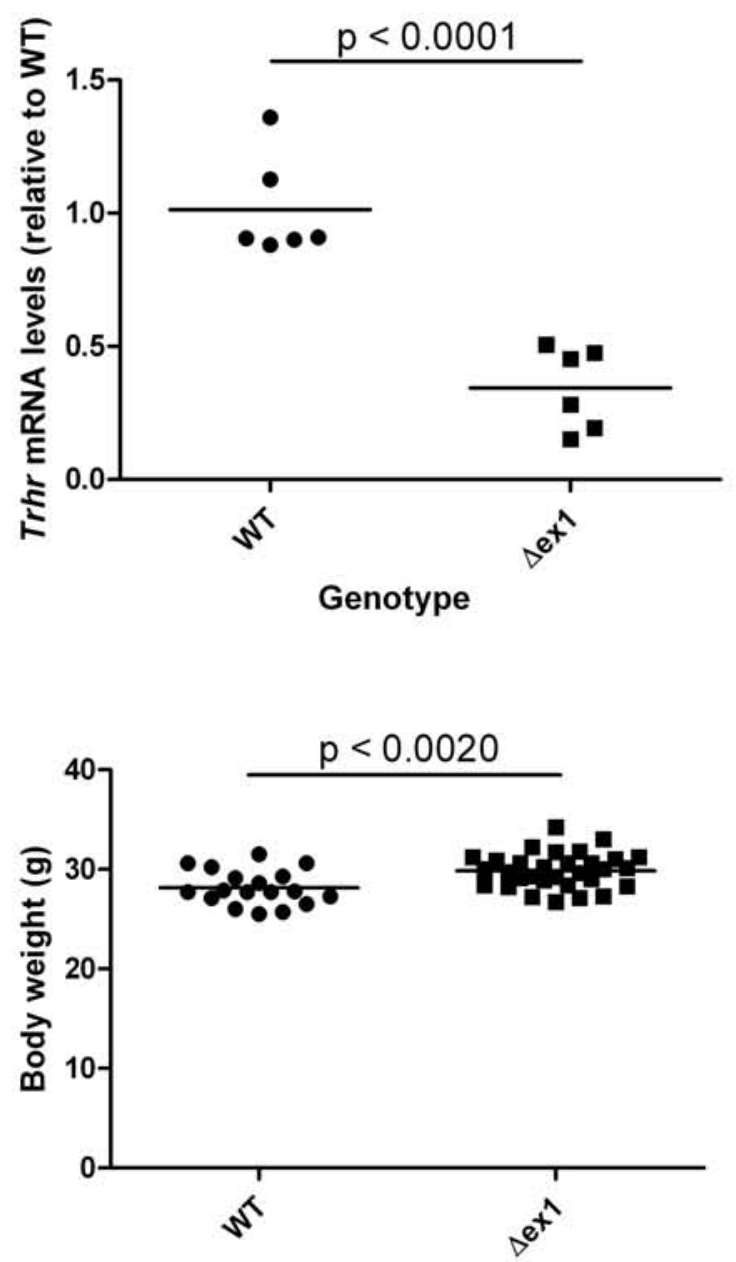

Genotype b

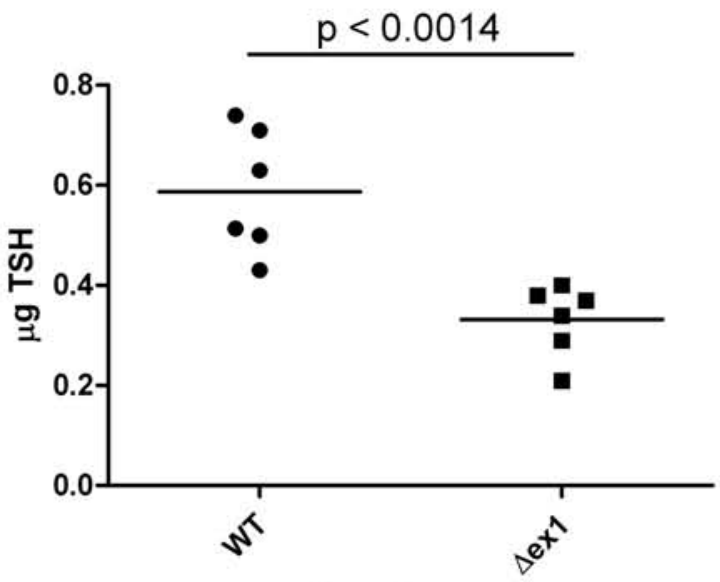

d
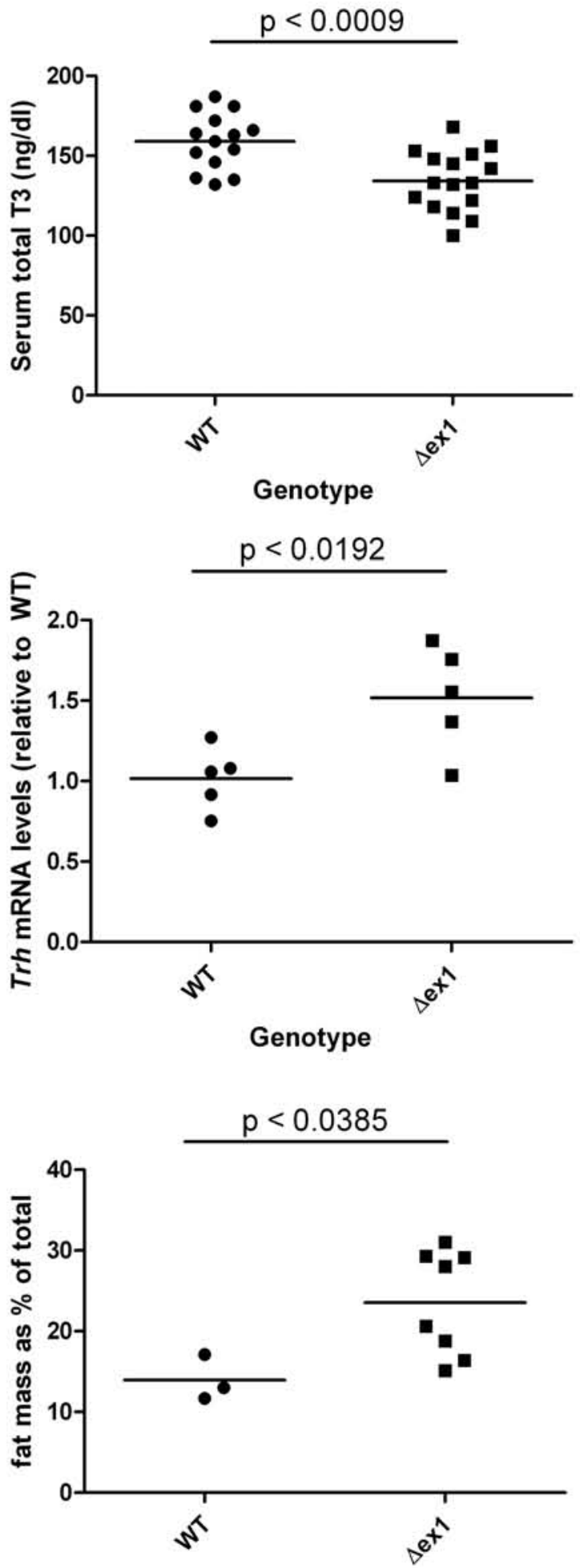

Genotype 